\title{
El origen de la cacica María y su familia. Una aproximación genealógica (Patagonia, siglos XVIII- XIX)
}

The origin of cacica María and her family. A genealogical approach (Patagonia, 18th and 19th centuries)

\section{Silvana Buscaglia}

\section{(2) OpenEdition}

\section{Journals}

\section{Edición electrónica}

URL: http://journals.openedition.org/corpusarchivos/2915

DOI: 10.4000/corpusarchivos. 2915

ISSN: 1853-8037

Editor

Diego Escolar

\section{Referencia electrónica}

Silvana Buscaglia, «El origen de la cacica María y su familia. Una aproximación genealógica

(Patagonia, siglos XVIII-XIX) », Corpus [En línea], Vol. 9, No 1 | 2019, Publicado el 02 julio 2019, consultado el 03 julio 2019. URL : http://journals.openedition.org/corpusarchivos/2915 ; DOI 10.4000/corpusarchivos.2915

\section{Este documento fue generado automáticamente el 3 julio 2019.}




\section{El origen de la cacica María y su familia. Una aproximación genealógica (Patagonia, siglos XVIII- XIX)}

The origin of cacica María and her family. A genealogical approach (Patagonia, 18th and 19th centuries)

Silvana Buscaglia

\section{NOTA DEL EDITOR}

Fecha de recepción del original: 19/09/2018

Fecha de aceptación para publicación: 12/11/2018

\section{Introducción}

1 En la segunda década del siglo XIX Península Valdés (provincia de Chubut) se había convertido en una suerte de Jardín de las Hespérides para la reproducción de ganado vacuno cimarrón. Este ganado fue introducido a partir de 1779 con la fundación del primer complejo de asentamientos coloniales establecidos en la península: El Fuerte San José y el Puesto de la Fuente, ${ }^{1}$ los cuales fueron destruidos por un malón indígena entre el 7 y 8 de agosto de 1810, al poco tiempo de producirse la Revolución de Mayo (Aragón 1810). ${ }^{2}$ Luego de este episodio, del que sólo habrían sobrevivido cinco individuos que se trasladaron al Fuerte Nuestra Señora del Carmen para buscar ayuda y relatar lo sucedido, los animales introducidos por los españoles comenzaron a pastar libremente. Sin embargo, la repentina abundancia de este recurso no pasó desapercibida para las poblaciones indígenas de la región ni para los comerciantes bonaerenses. Éstos últimos entre 1815 y 1825 organizaron numerosas expediciones a Península Valdés para explotar 
miles de cabezas de ganado bagual, lobos marinos y sal. Entre estos comerciantes se encontraba el galés Henry Libanus Jones, quien en 1824 formó una sociedad comercial junto a Luis María Vernet y otros hombres de negocios (Dumrauf 1991).

2 Al poco tiempo de establecer su base de operaciones en la costa y en el interior de la península, los comerciantes y los trabajadores percibieron que estaban siendo vigilados por los indígenas, quienes esperaban la llegada de su cacique. Cuando esta se produjo, no fue poca la sorpresa de Vernet al advertir que dicho cacique era en realidad una mujer. Conocida entre los criollos y europeos como María, se trataba de una líder de gran prestigio y poder entre los tehuelches, con quien Vernet debió negociar en duros términos la explotación de los animales a cambio mercancías y parte de su producción (Caillet-Bois 1948; Llarás Samitier 1965; Dumrauf 1991). Este encuentro sería el preludio de una posterior invitación para que la cacica visitara las Islas Malvinas y negociar la instalación de una factoría en Bahía San Gregorio (Vernet 1831; ${ }^{3}$ Fitz Roy 2016 [1839]; Llaras Samitier 1965; Álvarez Saldivia 2016), durante el período en que Vernet se desempeñó como gobernador de aquellas islas (1829-1831). ${ }^{4}$

Indagando en la bibliografía y la documentación histórica, María podría llegar a ser el único caso registrado -al menos hasta el momento- de una mujer detentando una jefatura indígena en la Patagonia meridional. En líneas generales, existen muy pocos antecedentes de jefaturas en manos femeninas en el ámbito pampeano -patagónico (Palermo 1994; Haurie 1996; Sosa 2001; Castillo Bernal y Videla 2003; Videla y Castillo Bernal 2003; Bandieri 2014; Videla 2007; Arias y Méndez 2008, entre otros). Posiblemente María llegó a ocupar un lugar de liderazgo entre los tehuelches meridionales como resultado de prácticas consuetudinarias relacionadas al carácter hereditario del poder, al menos en el caso de su familia y su linaje (Nacuzzi 2005, 2008; Videla 2007). Sin embargo, ello no habría resultado suficiente para alcanzar el reconocimiento que tuvo entre sus pares.

4 María supo entender los cambios que se estaban produciendo en la Patagonia de la primera mitad del siglo XIX de la mano del implacable avance del capitalismo internacional en la región. Entre otras cosas, organizó de forma sistemática el comercio activo con loberos y tripulaciones de todo tipo de embarcaciones que circulaban por la costa patagónica, entre las que podemos mencionar las que integraron la expedición hidrográfica al mando de los comandantes Pringle Stokes, Phillip P. King y Robert Fitz Roy. Fue precisamente la habilidad de María para relacionarse con marinos, exploradores, comerciantes y viajeros, uno de los principales aspectos que la han posicionado como un personaje singular y a la altura -en términos de estatus y poder- de renombrados caciques patagónicos.

5 Numerosos autores han abordado en mayor o menor medida la historia de María y las características de su liderazgo durante su adultez, por lo que constituyen antecedentes ineludibles a la hora de aproximarse a su biografía (Llaras Samitier 1954, 1965, 1985; Rey Timas 1960; Martinic 1995; Haurie 1996; Sosa 2001; Castillo Bernal y Videla 2003; Videla y Castillo Bernal 2003; Bandieri 2014; Videla 2007; Arias y Méndez 2008; Álvarez Saldivia 2016; Mayorga 2016, entre otros). Sin embargo, es llamativa la escasez y la dispersión de referencias respecto a su familia y los primeros años de su vida. Muchos autores, basándose en los viajeros que tuvieron contacto directo con la cacica, argumentan el origen mestizo y/o extra patagónico de esta mujer, llegando a señalar Paraguay como su lugar de nacimiento. Precisamente, es alrededor de esta dispersión y confusión que concebimos este trabajo. ¿Es posible conocer el origen de María? ¿Por qué los cronistas y la historiografía niegan su origen patagónico? ¿Fue más fácil asociarla a un origen 
mestizo que a uno indígena en tanto su condición de líder? ¿Se dieron los argumentos suficientes para respaldar estos supuestos? ¿Cuál fue el contexto en el que creció y moldeó su personalidad hasta convertirse en una respetada cacica?

6 Estos interrogantes dan cuenta de la necesidad de ampliar las fuentes de información investigadas y de una confrontación crítica entre diversos registros documentales para abordar la genealogía de María. Mis investigaciones sobre la estructuración de las relaciones interétnicas en el marco de la colonización española de la costa patagónica a fines del siglo XVIII (Alberti y Buscaglia 2015; Bianchi Villlelli y Buscaglia 2015; Buscaglia 2011, 2012a y b, 2015a, b y c, 2017; Buscaglia y Bianchi Villelli 2016, entre otros), han permitido reunir un corpus de información inédita relativa a la familia de la cacica y sus orígenes. Desde este punto de vista, presentaré argumentos a favor no sólo del origen tehuelche de María, sino de los vínculos que a fines del siglo XVIII su familia mantuvo con reconocidos marinos como Alejandro Malaspina y los establecimientos coloniales mencionados, especialmente con el de Puerto Deseado, provincia de Santa Cruz (Imagen № 1). Se incluye también una breve discusión sobre dos caciques que fueron identificados por diversos cronistas como hermanos de María, buscando particularmente desentrañar la identidad de uno de ellos, la cual sigue siendo poco clara hasta el presente. Más allá de la genealogía de la cacica, se busca contribuir al conocimiento de las relaciones tanto intra como interétnicas, y los territorios de los tehuelches meridionales en la transición de los siglos XVIII a XIX.

7 La reconstrucción biográfica de una figura histórica como María ha resultado un complejo desafío, no solo desde el punto de vista de la escasa disponibilidad, dispersión y contradicciones de las fuentes históricas relevantes al problema de investigación, sino también por el desequilibrio existente en la producción histórica y etnohistórica respecto a las poblaciones indígenas y el abordaje de las relaciones interétnicas en la costa atlántica de Patagonia meridional con respecto a Norpatagonia durante el período colonial, siendo considerablemente mayor en términos comparativos en esta última región (Gorla 1983; Irurtia 2002; Nacuzzi 2005; Luiz 2006; Davies 2009; Alioto 2011; Enrique 2011, 2012, 2018; Bandieri 2014, entre otros). 


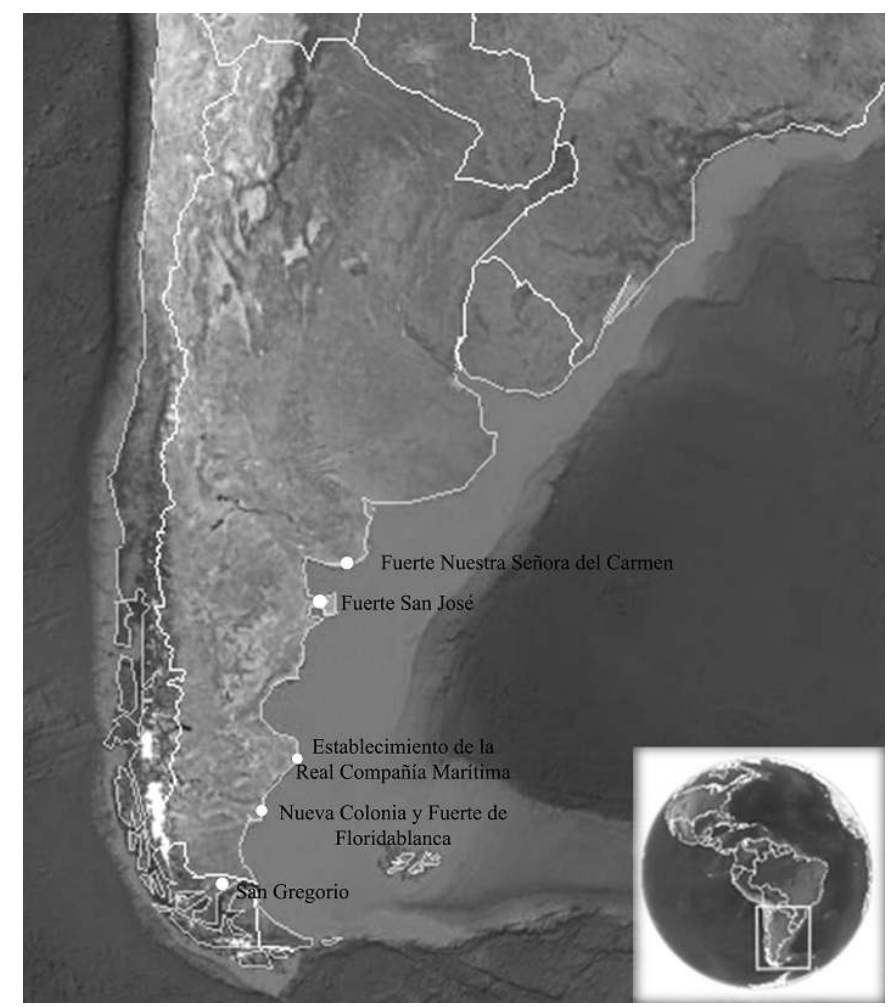

Imagen N ${ }^{0}$ 1. Localización de los enclaves coloniales españoles y el paradero de San Gregorio.

8 A continuación, se presentan las fuentes históricas abordadas y los criterios generales empleados en su análisis para luego entrar de lleno en la discusión sobre el origen de la cacica María y la reconstrucción de su red parental destacando los vínculos con las colonias españolas.

\section{Abordaje metodológico al corpus documental e historiográfico}

Sobre la base de los objetivos propuestos, realicé una extensa compulsa bibliográfica y documental con el fin de incorporar tanto información histórica inédita, fuentes éditas así como ampliar el abanico de autores y cronistas empleados. El abordaje implicó una confrontación crítica y comparativa entre diversos tipos de fuentes correspondientes a distintos períodos temporales. El objetivo fue encontrar silencios, inconsistencias, contradicciones y recurrencias no solo en la documentación histórica, sino entre ésta y la historiográfica (Mallon 1994; Johnson 1996; Jones 1999; Hall 2000, Moreland 2006, entre otros). Considero que esta es una de las maneras en la que es posible identificar y superar algunos los sesgos inherentes a las fuentes, como se ejemplificará en el desarrollo del trabajo. ${ }^{5}$ Este examen detallado de la documentación histórica fue imprescindible para dilucidar la genealogía de la cacica permitiendo no solo despejar algunas de las dudas sobre la primera etapa de su vida, sino trazar con claridad sus relaciones de parentesco y la trayectoria que siguió la misma.

En cuanto a las fuentes utilizadas, algunas de ellas se encuentran publicadas y son de fácil adquisición, otras pueden descargarse a través de internet, mientras que una gran parte fueron consultadas directamente o adquiridas digitalmente en repositorios como el 
Archivo General de la Nación (en adelante AGN), el Archivo General de Indias (en adelante AGI), Museo Naval de Madrid, Archivo General de Simancas (en adelante AGS), la Fundación de la Biblioteca Nacional de Río de Janeiro (en adelante FBNRJ), la Academia Nacional de la Historia, el Museo Etnográfico (Facultad de Filosofía y Letras-UBA) y el Repositorio Centro Científico Tecnológico, CONICET-CENPAT.

Entre las fuentes primarias inéditas, se analizaron distintos documentos identificados en los legajos correspondientes a la Sala IX, Costa Patagónica, Sección Gobierno, División Colonia; Sala X, Período Nacional, Documentos de Gobierno y Militares; Sala VII, Biblioteca Nacional y fondo Luis Vernet, todos ellos procedentes del Archivo General de la Nación, Buenos Aires. Los registros documentales sistematizados consisten en su mayor parte en cartas e informes escritos e intercambiados entre marinos españoles, funcionarios de las colonias españolas y autoridades virreinales. ${ }^{6}$

Asimismo, se procuró integrar al análisis todas aquellas fuentes primarias éditas en las que se registrasen referencias sobre la cacica María, su familia y parcialidades indígenas relacionadas (ver Tabla № 1). En su mayor parte corresponden a diarios de viaje de navegantes, naturalistas y misioneros escritos entre finales del siglo XVIII y las primeras décadas del siglo XIX. Para la segunda y tercera década de este último siglo se describen encuentros directos con una María ya adulta y posicionada como una poderosa cacica en Patagonia meridional. El hecho de que María sea una protagonista destacada y común en sus relatos da cuenta su trascendencia en la historia de los indígenas patagónicos, incluso muchos años después de producirse su fallecimiento.

Tabla № 1. Fuentes primarias éditas consultadas en las que se registraron referencias relacionadas con la cacica María.

Por último, el abordaje y el análisis de este corpus de información fue posible gracias a los trabajos, tanto académicos como no académicos -entre estos últimos, se contemplan incluso dos novelas históricas-, que no sólo se han preocupado por rescatar del olvido a María, sino de otorgarle el lugar que se merece en la historia de la Patagonia.

\section{El confuso origen de María}

Uno de los aspectos más llamativos que surge del análisis de las fuentes primarias editadas se relaciona con el presunto origen mestizo como extra-patagónico de María, el cual fue reproducido casi sin cuestionamiento hasta la actualidad. En el presente acápite presentaré y revisaré la información disponible para luego cuestionar dichas afirmaciones que por tanto tiempo han perdurado en la bibliografía y la memoria colectiva, presentando argumentos a favor de una ascendencia tehuelche para María.

En cuanto al origen mestizo de la cacica, fueron los loberos británicos Mathew Brisbane y James Weddell, quienes habrían perpetuado dicha idea cuando conocieron a María alrededor de 1820 en las costas de la Bahía de San Gregorio ${ }^{7}$ (provincia de Magallanes, Comuna de San Gregorio, Chile -Imagen № 1-), al regreso de su viaje de circunnavegación alrededor del polo antártico (Llarás Samitier 1965; Videla 2007).

En cuanto a los indicios sobre un origen no patagónico de la cacica, éstos pueden encontrarse en los diarios de viaje de los comandantes británicos Phillip Parker King (2015 [1839]) y Robert Fitz Roy (2016 [1839]) así como las referencias suministradas por el intrépido lobero escocés, William Low (Álvarez Saldivia 2016). Así, unos siete años después de las expediciones de Brisbane y Weddell, la Bahía de San Gregorio será 
nuevamente el escenario para el encuentro de María y su gente con la tripulación del buque oceanográfico HMS Adventure, el bergantín HSM Beagle y la goleta Adelaide, que integraron la exploración hidrográfica de las costas meridionales de América del Sur, en un viaje que constaría de dos etapas y abarcaría casi una década. No debemos olvidar tampoco que a bordo del Beagle se embarcó un joven Charles Darwin, quien durante la travesía reunirá los datos que inspiraron su Teoría de la Evolución y a quien María tratara durante su corta estadía en suelo patagónico (Darwin 2009 [1839]). Respecto de los orígenes de María, P. Parker King escribió en 1829:

Esta mujer notable debía tener, a juzgar por su apariencia, unos cuarenta años de edad; se dice que nació en Asunción del Paraguay, pero creo que su lugar de nacimiento debió haber sido más cerca de Buenos Aires. Hablaba español entrecortado pero inteligible, y decía ser la hermana de Bysante, el cacique de una tribu cercana al Río Santa Cruz, que es personaje importante debido a su estatura que María describía como inmensa- y su riqueza [el destacado me pertenece] (King 2015 [1839], p. 104).

18 Tanto el origen mestizo de María como un presunto lugar de nacimiento en "Asunción del Paraguay", es reforzada unos años más tarde por el comandante R. Fitz Roy, como se trascribe a continuación:

El individuo al que mayor atención se le prestó en ese entonces, una india mestiza llamada María, en una oportunidad persuadió a algunos de sus compañeros para que fueran con ella a las islas Falkland en una nave comandada por el señor Matthew Brisbane. Fueron, se quedaron allí unas semanas y regresaron en la misma nave, encantados con todas las novedades excepto por los mareos en la embarcación. El brujo principal de la tribu era uno del grupo. María era en ese momento una persona muy importante, ya que era prácticamente la única intérprete que tenían y la mujer de una persona de importancia. Su historia personal debe ser curiosa; nació en Asunción del Paraguay y tiene un hijo que es cacique [el destacado me pertenece] (Fitz Roy 2016 [1839], p. 142).

19 Llaras Samitier (1954) sugiere que el nombre cristiano de la cacica fue fruto de su bautismo en el Fuerte Nuestra Señora del Carmen (Carmen de Patagones, provincia de Buenos Aires -Imagen № 1-). Por su parte Aroldo Canclini, en una de las notas correspondientes al capítulo cuatro del diario de Williams Arm y Titus Coan agrega que la futura cacica fue bautizada como María de la Asunción -aunque no fundamenta el origen de este dato-, razón por la cual algunos autores y cronistas habrían asumido erróneamente que su nacimiento tuvo lugar en la capital paraguaya (Canclini en Coan 2006 [1886], p. 53). Como veremos más adelante, las observaciones de ambos autores podrían ser acertadas teniendo en cuenta que los circuitos de movilidad tanto de la banda de María como la de su padre se extendían desde el norte del Estrecho de Magallanes hasta el Río Negro. En este sentido R. Fitz Roy describe:

Muchas personas además de mí y de quienes me acompañan pueden atestiguar sus viajes. Algunos patagones a quienes oficiales del Beagle habían conocido personalmente fueron vistos por ellos en el establecimiento español -actualmente de Buenos Aires- del Carmen, cerca de la desembocadura de Río Negro, en septiembre de 1832; y por el Señor Low, en su lugar de residencia habitual, cerca del Estrecho de Magalhaens, en febrero de 1833 (Fitz Roy 2016 [1839], p. 142).

Ninguno de los navegantes citados suministra más información que permita averiguar el origen de las afirmaciones sobre el lugar de nacimiento de María. Rey Timas incluso sostiene - sin fundamentos- la existencia de relatos que afirman que María nació en Carmen de Patagones como resultado de la unión entre una indígena tehuelche y un español, habiéndose fugado la madre junto a la niña unos 10 o 12 años más tarde (Rey 
Timas 1960, p. 21). Como se desarrollará más adelante, las observaciones de José de Elizalde y Uztariz podrían desmentir esta versión (Elizalde y Uztariz 1938 [1792]).

Pero como si esta ambigüedad y confusión en torno sus orígenes no fueran suficientes, Estela Sáenz de Méndez en su novela histórica "María de las islas" título alusivo a María Sáenz de Vernet, sugiere un origen ona o selknam para la cacica:

Inmediatamente Vernet encontró la forma. Traería de Tierra del Fuego a la que llamaban La Reina del Estrecho (...)". Había oído comentarios sobre esa extraña mujer que con mano férrea manejaba a sus tribus de indios onas. Era la única hija de un cacique [el destacado me pertenece] (Sáenz de Méndez 1982, p. 31).

En la medida que fui rastreando hacia atrás en el tiempo los orígenes de María y de su familia, hallé información histórica de primera mano, que en un principio y si bien de manera indirecta, podría echar un manto de duda sobre las afirmaciones formuladas por los marinos británicos así como por posteriores autores. Desde este punto vista, como se desarrollará a continuación, se postula como hipótesis un origen tehuelche para María.

\section{Lazos de parentesco de la cacica María y primera infancia: Puerto Deseado como escenario destacado de la dinámica interétnica}

En este acápite me enfocaré en presentar todos aquellos indicios históricos -directos e indirectos- que permitan establecer el origen de María a partir de la información registrada sobre su familia y las parcialidades indígenas con los cuales ésta se emparentó o se relacionó. Ello a su vez permite trazar un cuadro más general de los líderes, los parentescos y las alianzas de los tehuelches meridionales a fines del siglo XVIII así como sus movimientos y paraderos más utilizados en el extenso territorio patagónico. La información analizada para este período es resultante principalmente de los informes generados tanto por expediciones españolas como aquellos producidos en el contexto de las colonias y fuertes creados en el marco del plan de poblamiento español en la costa atlántica patagónica. Si bien los indicios son fragmentarios, la sumatoria de los mismos a partir de la confrontación de distintas fuentes documentales, permite delinear con mayor precisión la genealogía de la cacica.

\subsection{La expedición de Malaspina y el encuentro con los tehuelches}

Los indicios más tempranos registrados hasta el momento sobre la parcialidad tehuelche a la que pudo haber pertenecido la cacica, se remontan a fines de 1789 y principios de 1790, teniendo como escenario Puerto Deseado, provincia de Santa Cruz (Imagen № 1), poco antes de la fundación del establecimiento de la Real Compañía Marítima. ${ }^{8}$ Allí fue donde la expedición de Alejandro Malaspina entabló a fines de 1789 un breve contacto con un grupo de "patagones" (Imagen № 2a), quienes manifestaron con insistencia su amistad con el reconocido marino de la Real Armada española, el Capitán y Piloto Don José de la Peña. Este piloto fue un exitoso mediador en el trato con los indígenas y un protagonista destacado en la empresa que fundó la colonia Floridablanca, Puerto San Julián, provincia de Santa Cruz (Imagen № 1) (Novo y Colson 1885; Priegue 1971; Sagredo Baeza y González Leiva 2004; Viedma 1972a [1783]). Al respecto, Malaspina señala:

Los que hablaron con los oficiales de la fragata Cabeza conocían al piloto Tafor, los que concurrieron con el Piloto Peña en el río Santa Cruz [provincia de Santa Cruz], 
eran los mismos que en las inmediaciones del puerto San José [provincia de Chubut] habrían sufrido nuestro choque injusto. ${ }^{9}$ Finalmente, el corto número que ahora estaba en el Puerto Deseado [provincia de Santa Cruz], conocía y había enlazado de parentesco con los del río Gallegos [provincia de Santa Cruz], y había llegado en sus excursiones hasta nuestro establecimiento de San José (Malaspina en Sagredo Baeza y González Leiva 2004, p. 224).

Este dato podría indicar que la familia de María pudo haber integrado o bien haberse relacionado con esta parcialidad, ${ }^{10}$ ya que la amistad con el piloto es un denominador común en los relatos posteriores. Asimismo, como se mostrará más adelante Puerto Deseado fue uno de los paraderos que la familia de la cacica visitaba con frecuencia. Tanto Malaspina (en Sagredo Baeza y González Leiva 2004), los hermanos Antonio y Arcadio Pineda $^{11}$ y el piloto José de la Peña integrantes de la expedición (en Priegue 1971 y Lehmann-Nitsche 1914), registran en sus relatos con el nombre de Junchar, Juncar o Jonchar al "Capitán Grande" o cacique principal con quien no solo tuvieron oportunidad de interactuar, sino también de retratar de la mano de José del Pozo (Imagen № 2b). De la Peña refiere que el cacique y su gente ya lo conocían previamente (De la Peña 1790). ${ }^{12} \mathrm{~A}$ excepción de estos oficios, no he podido identificar este nombre propio o su asociación con uno español en ninguna otra de las fuentes consultadas, por lo que la identidad del cacique resulta incierta.

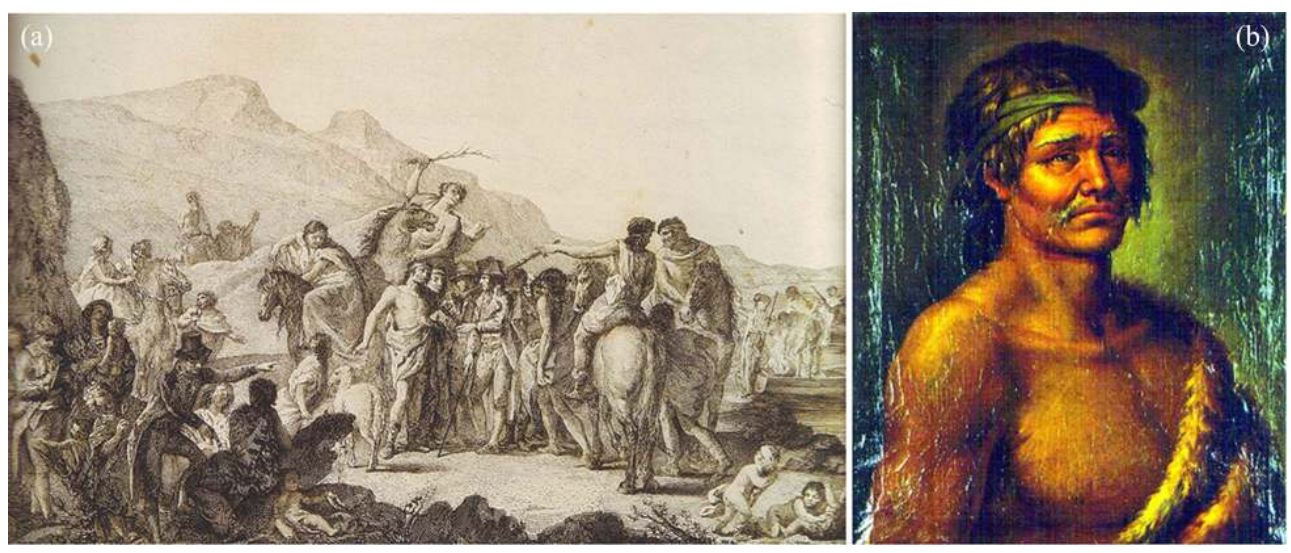

Imagen $N^{0}$ 2. a) Encuentro del capitán Malaspina con los indios patagones por José del Pozo, copia por Luis Planes (1792) y por Bartolomé Maura (tomado de Del Carril 1992, p. 65 en Novo y Colson 1885) y b) Retrato del cacique Junchar por José del Pozo realizado sobre apuntes tomados en Puerto Deseado en 1789, óleo sobre lienzo, Museo Naval de Madrid, nºatálogo 653.

Dentro de este grupo se destacaban dos mujeres que dominaban el castellano quizás como resultado de la relación con la colonia Floridablanca -abandonada en 1784- y el Fuerte San José, Península Valdés, provincia de Chubut (Imagen № 1) así como con los pilotos Bernardo Tafor ${ }^{13}$ y José de la Peña, como dejan entrever algunos datos suministrados por los expedicionarios (De la Peña 1790; Tova Arredondo en Sagredo Baeza y González Leiva 2004; Novo y Colson 1885, p. 66). Con respecto a la primera, si bien su nombre es omitido por Malaspina y Tova Arredondo, sí es consignado por De la Peña en uno de sus oficios, quien identifica como Jonafa a una indígena "de las más instruidas en nuestro idioma" (De la Peña 1790, folio 2). De la segunda sabemos que era una joven llamada Cahama (Pineda en Lehmann Nitsche 1914, p. 8) o Cátama, que sobresalía por su inteligencia, belleza y dominio del castellano. Al respecto el teniente de navío Antonio Tova Arredondo señala:

El trato que frecuentemente tienen con nuestro establecimiento de puerto San José y con algunas de las embarcaciones que suelen enviarse del Río de la Plata a esta 
costa y particularmente su buena disposición, le había puesto en estado de hacerse entender medianamente, no siendo tampoco extrañas muchas voces a las demás, dejándonos admirados de la facilidad de comprender y buena pronunciación de esta joven, al paso que ella no podía contener la risa siempre que nosotros equivocábamos o no acertábamos pronunciar algún término de su idioma, repitiéndonoslo después con todo el aire de maestra (Tova Arredondo en Sagredo Baeza y González Leiva 2004, p. 176). ${ }^{14}$

Malaspina estima la edad de la joven alrededor de 14 años según "pudimos deducir de las épocas de nuestras colonias en el Puerto Deseado ${ }^{15} \mathrm{y}$ en el de San Julián, ${ }^{16}$ con las que combinamos sus noticias" (Malaspina en Sagredo Baeza y González Leiva 2004, p. 224). Los nombres de estas dos mujeres no coincidirían con el de la madre de nuestra protagonista, quien también dominaba el castellano, teniendo en cuenta el dato suministrado por el marinero Francisco González (1965 [1798]), cómo se verá más adelante. Sin embargo, más allá de la identidad de estas indígenas, la información muestra una vez más el rápido dominio del castellano de los nativos patagónicos -particularmente entre las mujerescomo resultado de la interacción con las colonias españolas establecidas en el litoral atlántico a fines del siglo XVIII.

Antonio Tova Arredondo señala en su diario: "Esta tribu que se componía de 61 personas de todos los sexos y edades, debía marchar muy en breve para el Puerto de San Julián, donde la esperaba otra, con el fin de retirarse juntas hacia el sur" (Tova Arredondo Sagredo Baeza y González Leiva 200, p. 177). De acuerdo con el relato del teniente de navío, las distintas bandas durante el verano se dirigían hacia el sur, concretamente a las inmediaciones del Estrecho de Magallanes, donde se reunían y residían bajo el mando de un cacique con mayor poder (Tova Arredondo en Sagredo Baeza y González Leiva 2004). Esta observación es relevante si tenemos en cuenta que durante su adultez la cacica María ejerció su dominio directo en el territorio de la Bahía de San Gregorio en el Estrecho de Magallanes.

En el oficio del piloto José de la Peña encontramos una de las primeras referencias al cacique Vicente, señalado en la bibliografía como el padre de María (Sosa 2001; Videla y Castillo Bernal 2003; Videla 2007; Bandieri 2014, entre otros). En este documento el piloto refiere para el 20 de enero de 1790 la presencia en cercanías a la boca del río Santa Cruz (provincia de Santa Cruz) de un grupo de caciques amigos, lo cual refuerza su relación previa con los mismos, entre los que también se encontraban los hermanos del cacique Julián, como se transcribe a continuación:

El día 18 vimos en la parte Norte una fogata muy tierra adentro, pero a poco la vimos en la playa por la que fui muy prontamente y me hallé con dos indios bomberos, y habiéndolos agasajado, se fueron diciéndome iban a decirle a los caciques como estaba yo allí.

El 19 casi al oscurecer volvieron a encender fuego, pero por el mucho viento no pude ir en tierra hasta el siguiente día que habiéndolo ejecutado me hallé con los caciques Pecona y Patricio ${ }^{17}$ (hermanos de Julián que mataron los nuestros poco hace), Cheigua ${ }^{18}$ Vicente, Conoria y otros, todos amigos míos. Así que me vieron, me abrazaron, preguntándome por Don Antonio Viedma, por Tafor, y por otros de los que fuimos siempre muy queridos, viendo yo entre ellos al indio llamado Capón ${ }^{19}$ (que estuvo con Tafor en Montevideo y después por no salir del paquebote San Sebastián estuvo en Malvinas hasta que últimamente fue al Río Negro). ${ }^{20}$ Como tan instruido en nuestro idioma, le propuse venir a bordo y admitió en compañía de otro muy querido mío llamado Ocarauque [el destacado me pertenece] (De la Peña 1790, folio 9). 
La información generada en el marco de la expedición de Malaspina suministra valiosos datos respecto a las identidades de los tehuelches meridionales a fines del siglo XVIII, sus alianzas, sus paraderos, sus vínculos con las colonias patagónicas pero, por sobre todo, sitúa en este contexto a uno de los progenitores de María: el cacique Vicente.

\subsection{Relaciones con la Real Compañía Marítima (1790-1807)}

31 Poco tiempo después, Puerto Deseado volverá a convertirse en un escenario destacado de la dinámica interétnica entre los hispano-criollos y la familia de la cacica María, particularmente cuando se establece la Real Compañía Marítima (en adelante RCM) en noviembre de 1790. Allí, en tiempos de la colonia, España promovió el establecimiento de una factoría pesquera por cuenta de la compañía y un presidio militar a cargo de la Corona, frente a la creciente amenaza de balleneros y loberos ingleses en las aguas patagónicas (Imagen № 3a y b). Sus funciones estuvieron orientadas a la pesca de ballena, la caza de pinnípedos y la explotación de las salinas (Martínez Shaw 2008). El 10 de julio de 1803 la compañía fue clausurada por su bajo rendimiento, dejando un pequeño destacamento hasta 1807, año en que fue rescatado por un Bergantín de bandera norteamericana al mando del capitán Boucher y que fuera enviado por el comandante del Fuerte Nuestra Señora del Carmen, luego de las fallidas invasiones inglesas al Río de la Plata (Martínez 1807). ${ }^{21}$

32 El análisis de las relaciones interétnicas durante el funcionamiento de la Real Compañía Marítima, permitió registrar referencias dispersas en las fuentes documentales sobre las prácticas y el tipo de interacciones que la familia de la cacica y grupos indígenas relacionados, mantuvieron con los miembros de la factoría durante períodos más o menos prolongados de tiempo. Por cuestiones de espacio, aquí solo se reproducirán parcialmente algunos de los documentos en los que el cacique Vicente y su familia tienen un protagonismo destacado. ${ }^{22}$

A principios de 1791, el piloto José de la Peña en el marco de un reconocimiento conjunto de la costa patagónica con el Teniente de Fragata José Muñoz -comandante de la expedición de la RCM- refiere el encuentro para el intercambio de información entre los exploradores a su mando e indígenas patagónicos en las inmediaciones de la Bahía de San Julián. Entre estos últimos se encontraban una vez más "los caciques Coayujan, Olquincuenque, Conoria y Vicente" (De la Peña 1791, folio 7). ${ }^{23}$ La presencia de este último cacique en San Julián, puede ser considerada una vez más como un dato a favor de sus vínculos con el fallecido cacique Julián Camelo y la colonia de Floridablanca.

En cuanto a los indicios sobre el contacto con indígenas en el contexto de Puerto Deseado, las primeras referencias tienen lugar recién a casi un año de haberse establecido la compañía, siendo continuas hasta 1793. Luego, las menciones comienzan a espaciarse en el tiempo, registrándose únicamente en 1796, 1798, 1800 y $1807 .{ }^{24} \mathrm{El}$ análisis realizado en esta instancia preliminar indica que al menos durante los primeros años (1790-1793), las parcialidades indígenas con las cuales interactuaron los pobladores del enclave de Puerto Deseado, se asentaron durante períodos variables de tiempo en un paraje cercano al mismo con disponibilidad de fuentes de agua dulce y pasturas para los caballos. En cuanto a la frecuencia de las interacciones, mientras los indígenas permanecieron en las inmediaciones del establecimiento o incluso dentro del mismo, éstas habrían tenido un carácter casi cotidiano, similar a lo observado en los casos de los enclaves de 
Floridablanca y Nuestra Señora del Carmen (Nacuzzi 2005; Luiz 2006; Buscaglia 2011, 2012a y b, 2017, s.f., entre otros).
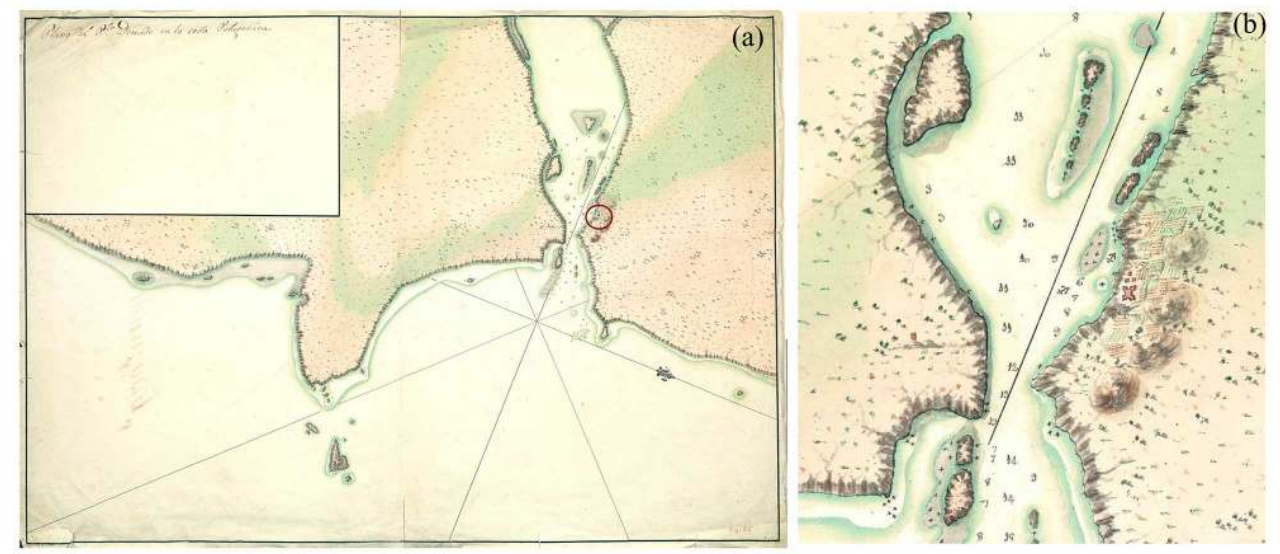

Imagen No 3. a) Plano de Puerto Deseado en la costa patagónica (el círculo demarca la localización del asentamiento) y b) detalle del asentamiento de la Real Compañía Marítima (Museo Naval, 48A-14).

La primera referencia sobre el contacto con una parcialidad de indígenas patagónicos se encuentra en el informe elaborado por el contador de la RCM, Don Nepomuceno de Victorica, el cual fue transcripto en su totalidad y publicado por Braun Menéndez (1947). En el mismo, el contador refiere que recién a los 10 meses de haberse creado el establecimiento de Puerto Deseado y unos cuatro días antes de su salida, se hizo presente una partida de indígenas. Este grupo estableció sus tolderías a dos leguas de la población, entablándose un activo agasajo e intercambio, ya que los indígenas surtían a los españoles con carne fresca de guanacos, pumas y ñandúes. De Victorica destaca en su relato que muchos de estos indígenas hablaban el castellano y otros lo entendían así como muchos de ellos mostraron familiaridad con las prácticas católicas, quizás como resultado de su relación con las otras colonias españolas (De Victorica 1790 en Bran Menéndez 1947).

En 1791 Juan Muñoz relata en un extenso oficio las por momentos tensas relaciones con los numerosos indígenas que frecuentaban el paraje de Puerto Deseado. Entre ellos se encontraba el cacique Vicente, quien es presentado como el interlocutor principal, tal como se transcribe a continuación:

Así los pude entretener por largos días pero siempre sufriendo infinitas impertinencias, obligándome a vivir en continuo cuidado para que no llevaran los útiles que había de nuestro uso. Además recibía de continuo nuevos Jefes que me presentara como introducción el Cacique Vicente, diciéndome eran sus aliados, Parientes o Amigos que venían a ver Cristianos: estos a su arribo y despedida habrían de ser regalados con Bebida, Yerba, Abalorios, Minestra y alguna Galleta irremediablemente, pues de lo contrario se mostraron quejosos en términos que destrozaran las huertas, ramoneando y pisoteando con sus caballos toda Planta y robando, si podían, algunos Platos de madera o cosa semejante, y si al siguiente día que volvían se le reconvenía a los Jefes contestaban que ellos no habían sido, y que pondrán reparo a que en adelante no sucediera tal: consiguióse así alguna mejora por algunos días mientras se daba algo, pero luego volvían a las andadas: con todas estas impertinencias sin reconocer otro daño mayor se pasó hasta principios de septiembre que se presentó el Cacique Vicente con un hermano de su madre que decía llamarse Archajal al cual le hice el acostumbrado agasajo de comida, y presentes, y diariamente venía a este establecimiento con varios de los suyos, sin que ocasionara novedad, hasta un día estando haciendo pan Miguel de Izardui, como no podía bajar por la multitud de Indios que había en la Panadería, vino a 
darme la queja que por haberles instado a que salieran de allí, este Archajal había sacado un daga para herirle, y a no haberle atajado uno lo hubiera ejecutado: con esta novedad hice juntar todos los caciques que había, previniéndoles con buenos modos el que se mostraran como amigos, y nos dejaran trabajar; híceles de nuevo regalos de algunas bujerías y un poco de Aguardiente para que se ausentaran cuanto antes (...) [el destacado me pertenece] (Muñoz 1791, folios 3-4). ${ }^{25}$ de conflictividad entre los españoles y los indígenas liderados tanto por Vicente como por otros caciques, en varias oportunidades ha sido posible observar, particularmente en el caso de las negociaciones entabladas con el primero, la obtención de mutuos beneficios en el marco de la ambivalencia característica de las relaciones interétnicas en Patagonia a fines del período colonial. ${ }^{26}$ Así, a cambio de diversos artículos y víveres el grupo del cacique se comprometía a abastecerlos con carne, pieles, agua, participar en la extracción de sal e, incluso, evitar la instalación de los ingleses en suelo patagónico. ${ }^{27}$ Es importante señalar que el cacique Vicente albergaba entre su gente un marinero británico como "esclavo", quien fuera rescatado por Juan Muñoz en su calidad de comandante del establecimiento de Puerto Deseado (Muñoz 1792; ${ }^{28}$ Arredondo $1793{ }^{29}$ ). Más allá de los anhelos de Muñoz en particular y de la corona española en general, los intereses de los tehuelches implicaron transacciones y relaciones comerciales, ${ }^{30}$ tanto con la tripulación de embarcaciones británicas como de otras nacionalidades, tal como lo demostraría ampliamente la misma María unos años más adelante. ${ }^{31}$

ejemplo de esta clase de interacciones es el reporte del Capitán Juan Gutiérrez de la Concha cuando en 1794 recala en Puerto Deseado para reponer agua. Según menciona en su diario, esta faena estuvo a cargo de las mujeres del grupo del cacique Vicente "cuya mujer amiga del Piloto Peña lo ordenó -para lo que se dio a cada una de aquellas, un barril que transportaron lleno a la playa desde los pozos distantes dos leguas del puerto [alrededor de 14 kilómetros]" (Gutiérrez de la Concha en Ratto 1930b, p. 188). Por su parte, dos años más tarde el piloto José de la Peña en su informe de 1796 señala para Puerto Deseado:

39 Es paraje que concurre bastante Indiada a contratar con mantas de pieles de guanaco, zorrillo, leopardo y potrillo que los cambian por galleta, bujerías, y aguardiente, que es el vicio que los domina, y se los facilitan los que existen de la misma Compañía Marítima (Peña 1796a y b). ${ }^{32}$

El diario del marino Francisco González (1798) representa un ejemplo más para fortalecer los argumentos a favor de la estrecha relación que el grupo del cacique Vicente mantuvo con el establecimiento de la RCM en Puerto Deseado. En 1798 los padres de María y su grupo realizaron un viaje por tierra hacia el Fuerte Nuestra Señora del Carmen, con el objeto de entregar a su comandante, Don Joaquín Maestre, unos pliegos informando sobre las carencias que experimentaba el asentamiento. Habiendo partido desde Puerto Deseado el 20 de agosto de 1798 el propio González apunta: "Salí acompañado del Cacique llamado Vicente que con muchos toldos se dirigía al Río Negro y con quien trató el comandante fuese en su campaña para entregarle un pliego a aquel comandante avisándole de la extrema necesidad en que nos hallábamos" (González 1965 [1798], p. 21). El autor del diario incluso refiere que la mujer del cacique Vicente se llamaba "Cogocha" (González 1965 [1798], p.39), desconociendo por el momento si tiene relación o no con la mujer llamada Jonafa, mencionada por De la Peña ocho años antes (1790). ${ }^{33}$ 
41 Durante el tiempo que duró el viaje, aproximadamente unos 115 días, Vicente y su gente asistieron a los expedicionarios con información, caballos y alimentos. Incluso se celebró un casamiento durante una de las paradas de la travesía hacia el Fuerte Nuestra Señora del Carmen, la entrada a la pubertad de una niña así como la prematura muerte de otra. González aporta datos de interés respecto de las relaciones entre los tehuelches meridionales, al mencionar la amistad entre Vicente y el cacique Patricio, hermano del cacique Julián Camelo así como los paraderos visitados por estos indígenas en sus desplazamientos hacia el norte de Patagonia. Permanentemente, a lo largo de todo el trayecto el cronista menciona la llegada y la agregación de toldos amigos de Vicente, como los de los caciques Conoria, Sapa, Capón, entre otros, mencionados seis años antes por Elizalde. El diario deja trascender la asistencia que tanto Vicente como otros caciques, brindaron a los expedicionarios durante el período en el que se prolongó el viaje.

\subsection{Los primeros indicios sobre María: la expedición de Juan José de Elizalde y la interacción con su familia}

Los detalles relativos a la infancia y la temprana juventud de María son muy escasos. Las únicas referencias conocidas hasta el momento fueron registradas en 1792 por el teniente de navío Juan José de Elizalde y Uztáriz al mando de la corbeta San Pío en su Diario de Navegación, rico en detalles etnográficos sobre los indígenas patagónicos-fueguinos, aunque curiosamente una fuente escasamente citada e investigada. ${ }^{34} \mathrm{~A}$ pedido de Malaspina, se trató de un viaje exploratorio a Tierra del Fuego dirigido a examinar la costa patagónica y fueguina hasta el Cabo de Hornos, identificando durante el trayecto posibles asentamientos británicos. La misión finalizaría en la Isla Soledad, donde José de Elizalde y Uztariz asumiría nuevamente como Gobernador de las Islas Malvinas entre 1792 y 1793 (Segura 1973; Caviglia 2012).

Elizalde ${ }^{35}$ y su tripulación desembarcaron en Puerto Deseado el 3 de enero de 1792 y durante los 15 días de su estadía habrían entrado en contacto con los progenitores de María: "vinieron el tal Vicente, su mujer (que es muy despejada y ladina), la hija llamada Mariquita (...)" (Elizalde y Uztariz 1938 [1792], p. 273). El apodo de Mariquita podría ser un diminutivo de María, aunque lamentablemente no se ha registrado el nombre tehuelche de la niña. En función de la información suministrada en el diario de viaje de P. P. King donde señala que para 1829 María tendría unos 40 años de edad (King 2015 [1839]), es posible entonces especular que al momento del encuentro con Elizalde fuera una niña de alrededor de unos 3 años, estimando su fecha de nacimiento cercana al año de 1789.

La infancia de María habría transcurrido a fines del siglo XVIII en un contexto en el que tanto los españoles como otras potencias europeas incrementaron su interés sobre la Patagonia, no sólo desde el punto de vista de la creación y afianzamiento de enclaves coloniales sino también de la explotación de los recursos que ofrecía fundamentalmente el mar. Las poblaciones indígenas patagónicas no estuvieron ajenas a estos cambios, buscando capitalizar la relación con los extranjeros en términos de sus propios beneficios, ${ }^{36}$ lo que también fue un denominador común a lo largo de la vida de nuestra protagonista.

Volviendo al encuentro entre la expedición de Elizalde y la familia del cacique Vicente, según la crónica el mismo tuvo lugar el 4 de enero de 1792 en el área donde se emplazó el establecimiento de la Real Compañía Marítima. El teniente de navío refiere que ese día: 
(...) vino toda la Indiada de las inmediaciones, que se compondrá como de 400 o 500 personas, hablé con el Comandante Marién ${ }^{37}$ y al Capitán del Bergantín Peña, para que me enviasen a bordo los Caciques, y personas principales que conocían para obsequiarlos y tenerlos gratos, vinieron con el primero los siguientes: Coayuja ${ }^{38} \mathrm{y}$ Vicente, hermanos del Cacique general de la tierra llamado Chegües, ${ }^{39}$ que se halla ausente, otros dos caciques nombrados Conoria y Capón, con sus mujeres e hijos, ascendiendo en todo a once personas; se les dio muy bien de comer en la cámara, después de tomado mucho mate, que lo aprecian en extremo, siendo servidos con el mayor agrado por mí y mis oficiales (Elizalde 1938 [1792], p. 264). ${ }^{40}$ caciques y sus respectivas familias, repitiéndose las visitas casi diariamente hasta que la corbeta parte hacia Tierra del Fuego. En una de estas tantas visitas, Elizalde aporta un dato curioso como importante, en el que se refiere a la tenencia por parte de Vicente de una pequeña figura de Cristo:

Vinieron algunos indios, y entre ellos el Cacique Vicente que hace tres días está con el ansia de que un Cristo que tiene (que se lo dio Muñoz, el comandante de los Balleneros) le está siempre hablando y diciendo tener hablar capitán Carro Grande, lo que me hicieron presente Marién y Peña, a quienes dije lo trajeran a bordo con algunos de sus amigos y principales; en efecto, vinieron el tal Vicente, su mujer (que es muy despejada y ladina), la hija llamada Mariquita y los caciques Conoria y Capón. Traía el dicho Vicente un Crucifijo de estaño sobre madera de un palmo de largo, y luego que entró en la cámara me lo enseñó, y tomándolo yo lo besé con reverencia en los pies, y pasándolo para que cada uno de ellos hicieran la misma ceremonia significándoles yo por señas, que aquél era Dios, Señor del Cielo y Tierra, que sirviéndole y amando, llevar al cielo después de muertos, a que me respondieron ellos: indios morir y no más, dando a entender la mortalidad de sus almas con sus cuerpos; les hice besaran segunda vez los pies del crucifijo con toda veneración, a ejemplo de los que estábamos en la cámara, encargándole lo cuidara y quisiera mucho, diciéndole: estar gran Señor y querer muchos indios. Seguidamente habló Vicente lo siguiente: Cristo decir, fumar indios todos, comer harina poquilla venir Carro grande; queriendo decir con esto que el crucifijo le había dicho repartiera entre la indiada un poco de tabaco y harina que tenía, porque luego vendría una embarcación grande. Se les dio muy bien de comer y varios regalos, con lo que se fueron a tierra no tan contentos, según supe, como se prometían a la ida a bordo. En vista de lo que mandé darle un Samay de bizcocho con alguna más menestra y mate, que les acabó de contentar (Elizalde 1938 [1792], p. 273).

Cabe destacar, que la figura del Cristo vuelve a reaparecer años más tarde en manos de María cuando se relaciona con la expedición del Beagle y el Adventure (1826-1836) así como con los misioneros norteamericanos Titus Coan y William Arms (1833-1834). Al respecto, en 1827 en una visita al campamento indígena en la Bahía de San Gregorio, P. P. King señala:

Cuando María regresó con una cantidad pequeña de carne de guanaco, su marido le contó que me había mostrado muy inquisitivo sobre un bulto de paño rojo, que según me dijo contenía a 'Cristo', tras lo que María me preguntó: '¿Quiere mirar mi Cristo?'. ${ }^{41} Y$ después de que asentí, llamó a su alrededor a varios de la tribu, que inmediatamente respondieron a su convocatoria (...) quitó dos o tres envolturas y expuso ante nosotros una pequeña figura tallada en madera, que representaba a una persona muerta tumbada. Después de exponer la imagen, a la que todos prestaron mucha atención, y contemplarla un tiempo en silencio, María comenzó a disertar sobre las virtudes de su Cristo, diciéndonos que tenía un 'buen corazón' ${ }^{\prime 2}$ y que le gustaba mucho el tabaco. 'Mucho quiere mi Cristo tabaco, dame más'. ${ }^{43}$ No podía rechazar un pedido como éste en una ocasión semejante; y después de aprobar su alabanza de la figura, le dije que mandaría a buscar un poco a bordo. 
Luego de salirse con la suya, comenzó a hablar para sí misma, y miró hacia arriba, tras repetir las palabras 'Muy bueno mi Cristo, muy bueno corazón tiene', ${ }^{44}$ y lenta y solemnemente envolvió la figura, y la depositó en el lugar del que se la había sacado. La ceremonia terminó, y el comercio, que había sido interrumpido, se reanudó con una actividad más intensa (King 2015 [1839], pp. 107-108).

\section{desarrollada entre 1831 y 1836, las observaciones de P. P. King sobre el Cristo que poséa} la cacica María son ratificadas en el siguiente pasaje:

La tribu o subgrupo de los tehuelhet que suele vivir cerca del Estrecho de Magalhaens ha aprendido a rendir una especie de homenaje -quizás se lo podría llamar culto- a una imagen de madera tallada con la forma de la cabeza y el cuerpo de un hombre, al que llaman Cristo; esta imagen rara vez la sacan frente a extraños, o incluso entre ellos, excepto cuando hay una muerte o en ocasiones muy particulares. Este intento de una abierta demostración de fe según las costumbres de la iglesia papista parece haber sido provocado por un tal capitán Pelippa, que visitó el Estrecho de Magalhaens un tiempo antes que la Adventure y el Beagle. No logré descubrir quién era ni qué hacía (Fitz Roy 2016 [1839], p. 155).

Durante su corta estadía en Patagonia hacia fines de 1833 y principios de 1834, los misioneros Williams Arms y Titus Coan refieren: "También se dice que María tiene una pequeña imagen que exhibe ocasionalmente y perforando su carne hace fluir la sangre (... )"45 (Coan 2006 [1886], p. 201).

Resulta imposible dejar de notar la semejanza entre esta ceremonia y las demandas canalizadas a través del Cristo que el cacique Vicente efectuara ante Elizalde unos 35 años antes. Considero que se trata de un dato de importancia para argumentar a favor de la relación parental entre Vicente y María. La conservación del Cristo en manos de María así como el uso de medallas con la imagen de la virgen como aros, ${ }^{46}$ da cuenta de la importancia y el significado que tuvieron ciertos objetos exógenos entre los tehuelches, atestiguado por su trasmisión y resguardo a través de las generaciones, en tanto símbolos materiales asociados a la religiosidad, al poder y la diferenciación social (Castillo Bernal y Videla 2003; Bandieri 2014). A su vez, la información transmitida por Elizalde de alguna manera permite dudar del posible adoctrinamiento en la fe católica por parte de un ignoto capitán Pelippa, mencionado por Fitz Roy.

51 Volviendo a fines del siglo XVIII, las descripciones volcadas por Elizalde en su diario son refrendadas en parte por Don Manuel Lefrant y Fernández, quien fuera a bordo de la Corbeta San Pío en calidad de contador del navío. A su arribo a la isla Soledad de Malvinas, Manuel Lefrant redactó una carta dirigida a Don Pedro Álvarez Caballero, en la que entre otras cosas, describe la relación que durante 15 días mantuvieron con los indígenas cuando arribaron a Puerto Deseado:

Uno de sus caciques llamado Esteban Sacos y por otro nombre Capón ${ }^{47}$ y otro mozo llamado Chaquiala, bien racional y el más instruido y juicioso, hablan y entienden regularmente el Castellano, y no dejan de tener alguna idea de Dios: el primero porque anduvo por aquí (Malvinas), Buenos Aires y Montevideo con un gobernador que fue de estas Islas; $y$ el segundo porque fue civilizado por un Superintendente de Patagónica, pero no pasan de aquí (Lefrant y Fernández en Segura 1974, pp. 290-291).

Si bien no menciona Lefrant en su carta a Vicente y su familia, sí hace referencia a los caciques aliados como por ejemplo Capón y, sobre todo, destacamos la alusión a la estrecha relación de los tehuelches con las colonias patagónicas. En este sentido, el joven llamado Chaquiala, ${ }^{48}$ donde además de destacar su dominio del castellano, ${ }^{49}$ es identificado 
por Elizalde (1938 [1792]) como un miembro del grupo del cacique Vicente e hijo del cacique Orguinguengue..$^{50} \mathrm{La}$ evidencia reunida hasta el momento parecería indicar que Vicente, Capón, así como los hermanos Patricio y Julián Camelo fueron aliados, aunque estos dos últimos mantuvieron relaciones ambivalentes con los otros tres establecimientos creados en el marco del plan de colonización de la costa atlántica patagónica. Ello se manifiesta en el hecho de encontrar a algunos de ellos -incluyendo los hijos de los caciques hermanos, Julián Camelo y Patricio, reunidos en el paraje donde se emplazó el enclave español de Puerto Deseado así como durante el viaje de Francisco González al Río Negro (Muñoz 1791; Elizalde 1938 [1792]; González 1965 [1798]). Como señala Liliana Videla "al hablar sobre la organización social de los tehuelches meridionales hacemos referencia a caciques que alcanzaban tal categoría a través de las relaciones de parentesco que los vinculaban con otros caciques. Es decir que el poder estaba asociado con la pertenencia a esas familias" (Videla 2007, p. 30).

Quizás una curiosa y “agraciada” Mariquita como la describe Elizalde (1938 [1792], p. 274), desde temprana edad aprendiera de sus padres el arte de relacionarse y negociar con los europeos que visitaban sus territorios. Las interacciones más estrechas fueron con los hispano-criollos que habitaron las colonias y factorías españolas establecidas a lo largo de la costa patagónica a fines del siglo XVIII, como dejan trascender numerosos documentos de la época.

\section{Algunas consideraciones acerca de los hermanos de la cacica María}

Si bien en las crónicas tempranas no se han registrado referencias sobre otros descendientes de Vicente y Cogocha a excepción de Mariquita, en los relatos posteriores se reconocen al menos dos hermanos de María, cuyas identidades trataremos de establecer en este acápite. Teniendo en cuenta la práctica de la poligamia entre los tehuelches meridionales, no debe descartarse la posibilidad de que no compartieran la misma madre así como la de un mayor número de hermanos, que no han sido reconocidos y/o descriptos en las fuentes consultadas. Uno de los hermanos de María es identificado de forma no ambigua por diversos cronistas como Bysante, Bicente o Vicente. El otro en cambio, resulta más elusivo en las fuentes investigadas, pudiendo tratarse del cacique Wissale, Huisel, Congo o Konger, entre los tantos nombres con los que se lo conoció. En las descripciones analizadas, ambos se destacan por su gran estatura y fortaleza física, características que habrían heredado de su padre así como el control de distintos territorios en la Patagonia meridional. Uno de los primeros cronistas en dar cuenta de los dos hermanos de la cacique es P. P. King, quien en mayo 1827 señala en su diario:

(...) y decía ser hermana de Bysante, el cacique de una tribu cercana al río Santa Cruz, que es un personaje importante debido a su estatura -que María describía como inmensa- y su riqueza. Acerca de él dijo que era 'muy rico, que tiene muchas mantas y también muchos cueros' ${ }^{51}$ Uno de los acompañantes de María, un hermano de Bysante, era el hombre más alto y corpulento de su tribu [...]. Estaba pasando por un momento de mucho dolor, ya que su hija había muerto apenas dos días antes de nuestra llegada. (...). Cuando acudimos a María, que no había tomado tanto como su hermano, para que impidiese que siguiera haciendo esos sonidos terribles, se rió y dijo: 'Es borracho, pobrecito, murió su hija'52 (...). [el destacado me pertenece] (King (2015 [1839], pp. 104-105). 

Cacique Grande", agregando que la superioridad de María, en realidad podría provenir de su parentesco directo con este cacique (King 2015 [1839], p. 117). Resulta difícil establecer la etimología de "Bysante", aunque la proximidad fonética con Vicente resulta más que evidente. El relato de P. P. King es el único testimonio registrado hasta el momento en el que se mencionan los hermanos de María en el marco de la expedición hidrográfica británica; ni R. Fitz Roy ni C. Darwin hacen mención alguna al respecto en sus respectivos informes y diarios de viaje.

en carmen de Patagones, el naturalista francés Alcide d'Orbigny tuvo oportunidad de conocer e interactuar con distintas parcialidades étnicas que se asentaban en los alrededores del asentamiento, principalmente con el objeto de comerciar. Entre estos grupos, los tehuelches meridionales fueron asiduos visitantes desde la fundación del asentamiento en 1779. En una de sus frecuentes visitas a las tolderías de estos últimos durante su estadía en 1829, D'orbigny registró tres veces en su diario al cacique Bicente, así como el arribo de tehuelches procedentes del Estrecho de Magallanes. En la primera de estas oportunidades consigna: "El carasken que conocí en mi viaje, llamado Bicente, había reemplazado, dos años antes de mi llegada, a otro cacique famoso por su alta estatura, su fuerza y sobre todo por sus modales llenos de grandeza" (D 'Orbigny (1999 [1839-1847], p. 324). Es posible especular que el cacique al cual reemplazó Bicente, haya sido su padre, teniendo en cuenta el carácter en ocasiones hereditario de las jefaturas entre los indígenas patagónicos así como de los nombres de quienes las detentaban (Nacuzzi 1998; 2005; 2008; Videla 2007). Asimismo, el naturalista consigna más adelante en su diario que el cacique Vicente -escrito esta vez con "v"- era el primer jefe de los patagones, nombre por el que era conocido en el establecimiento de Carmen de Patagones (D'Orbigny (1999 [1839-1847], p. 430). Finalmente, al igual que P. P. King, menciona que Vicente tenía un hermano:

El 8 de agosto regresó Lucaney de su misión junto al jefe Patagón; trajo a un hermano del famoso cacique Vicente y a muchos otros indios, con los cuales quedamos en pie de amistad. Un desertor chileno, que los acompañaba, fue reconocido por nuestro explorador salvado de las manos de Chaucata, como el que pidió la muerte de sus camaradas [el destacado me pertenece] (D'Orbigny 1999 [1839-1847], p. 456).

57 Sin embargo, llama la atención que D’Orbigny omitiera mencionar a María, quien ya por esas fechas detentaba su poder sobre una vasta extensión del territorio patagónico. Las incongruencias y los silencios en las fuentes, refuerzan la necesidad no solo de tomarlas con cautela sino de confrontar el mayor número posible de las mismas en la medida que las investigaciones continúen avanzando.

Con respecto al otro hermano mencionado tanto por P. P. King como D'Orbigny, no he podido registrar ninguna otra referencia certera entre las fuentes consultadas hasta el momento. No obstante, si nos adentramos en el terreno de las especulaciones sobre la base de ciertos indicios, el nombre de Wissale, Wesail, Congo o Kongre, entre las múltiples denominaciones con las que se lo conoció, surge como posible candidato a segundo hermano de María, en especial teniendo en cuenta la coincidencia de la mayor parte de los relatos sobre sus características físicas. A continuación, trataremos de desentrañar sus vínculos con la cacica.

En su libro "Mujeres indígenas de la Pampa y la Patagonia", Norma Sosa propone que Wissale o Wesail, podría ser una deformación de Bysante y tratarse, por lo tanto, de la misma persona (Sosa 2001, p. 318). Si bien es una hipótesis plausible, la autora

Corpus, Vol. 9, No 1 | 2019 
lamentablemente no profundiza en la misma. A favor, se podría esgrimir que en las fuentes en las que se menciona a Wissale, Bysante no aparece mencionado y ambos comparten el rango adjetivado de "capitán grande", aunque se trataba de un adjetivo de uso común entre los caciques. Es posible también que los cronistas norteamericanos y franceses no hayan registrado su nombre español.

Sin embargo, si atendemos a los detalles que brindan Phillip. P. King (2015 [1839]), Titus Coan (2006 [1880]), Dumont d'Urville (1841 en Bahamonde Gallardo 2017), Aller Gardiner (en Marsh 1857) y Robert Hunt (1844-1845) en sus relatos en cuanto al dominio territorial de ambos individuos, podría no tratarse de la misma persona. De acuerdo a P. P. King (2015 [1839]), Bysante o Vicente habría dominado el territorio en torno al río Santa Cruz; por el contario de acuerdo a la información suministrada por Titus Coan, Dumont d'Urville y Allen Gardiner, Wissale compartió el liderazgo con María en el área de la Bahía de San Gregorio, ${ }^{53}$ hasta que luego de su muerte posiblemente la sucedió en el poder, como uno de los caciques principales. La reproducción vertical y horizontal de las jefaturas -caciques hermanos-, al menos dentro de esta parcialidad de tehuelches meridionales, como señala Nacuzzi podría estar dando cuenta de linajes de familias que detentaban cacicazgos en una región determinada (1998, p.184).

Entre las fuentes que brindan más detalles sobre la figura de Wissale se encuentran los diarios e informes escritos por los misioneros norteamericanos Titus Coan y Williams Arms (Coan 1833-1834; 1880; Coan 2006 [1880]). Con el fin de emprender acciones de evangelización entre los indígenas patagónicos, los misioneros arribaron a la Bahía de San Gregorio en noviembre de 1833, permaneciendo en el Estrecho de Magallanes hasta marzo de 1834. Allí fue donde entraron en contacto con el grupo de la cacica María así como con otras parcialidades entre las que se encontraba la del "Gran jefe Congo" o "de capita le grande" (Coan 2006 [1886], p. 87). Vale aquí observar el uso recurrente del adjetivo "grande" acompañando al rango de Bysante cuando es descripto en la crónica de P. P. King (2015 [1839]) y Congo, lo cual da cuenta por lo menos de la importancia del liderazgo de cada uno de ellos. Congo se habría presentado ante los misioneros como el "gran jefe de la tribu", quienes destacaron:

Es un espléndido ejemplo de estructura física, de un metro noventa de alto, bien formado y agradable figura y movimientos. Tiene una apariencia suave y abierta, con una estampa de intelectual, así como pleno de gentileza y buen carácter (...). Habla muchas palabras castellanas y algunas inglesas y se considera un hombre preparado, especialmente porque puede contar hasta diez en inglés. Nos dijo que una gran parte de su tribu estaba con Santa María y que estarían aquí en una luna ( Coan 2006 [1886], p. 87). ${ }^{54}$

62 Vale la pena recordar las observaciones de P. P. King citadas al comienzo del acápite, respecto a la destacada altura y estructura física de ambos hermanos de María. Congo, por su parte, tiene un protagonismo central en los relatos de los misioneros, quienes subrayan una evidente rivalidad de poder entre él y María, aportando un dato de importancia en cuanto a la diferencia de edad entre los dos líderes como se transcribe a continuación:

Ahora Congo se ve como un adulador mañoso e insinuante y su influencia está en aumento, mientras que la de María está decayendo. Sin duda, al menos en cierto modo, esto surge del hecho de que él es joven, vigoroso y activo, con una buena estampa y un porte valeroso, mientras que, por el otro lado, Santa María es de edad avanzada, de apariencia menos fascinante y con menos actividad y coraje (Coan 2006 [1886], p. 122). 
documento fechado en julio de 1834 y dirigido al secretario de la American Board of Commisioners for Foreign Missions (A.B.C.F.M) en Boston, alguno de los dos misioneros (ya que no está firmado) señala que María ya había perdido su autoridad y que la misma ahora se encontraba en manos de Congo (Coan 2006 [1886], p. 200). El caso de María y Congo podría estar representado un ejemplo tardío de cacicazgo dual, ya que en las fuentes se reconoce que ambos ejercían su autoridad sobre un mismo grupo y territorio (ver Nacuzzi 1993-94, 2005, 2008).

Conviene aquí señalar la similitud fonética entre "Congo" y el "Konger" o "Kongre" registrado Dumont d 'Urville en su paso por el Estrecho de Magallanes unos tres años más tarde, entre diciembre de 1837 y enero de 1838 (Dumont d'Urville 1841 en Bahamonde Gallardo 2017). A semejanza del contacto con los misioneros norteamericanos, los expedicionarios franceses destacaron la estatura del jefe principal $-1,87 \mathrm{~m}$ - y señalaron que rondaría los 30 años de edad, dejando en claro que Konger conocía el castellano y el inglés (Bahamonde Gallardo 2017), información que permite especular que estaríamos ante la misma persona (Imagen № 4).

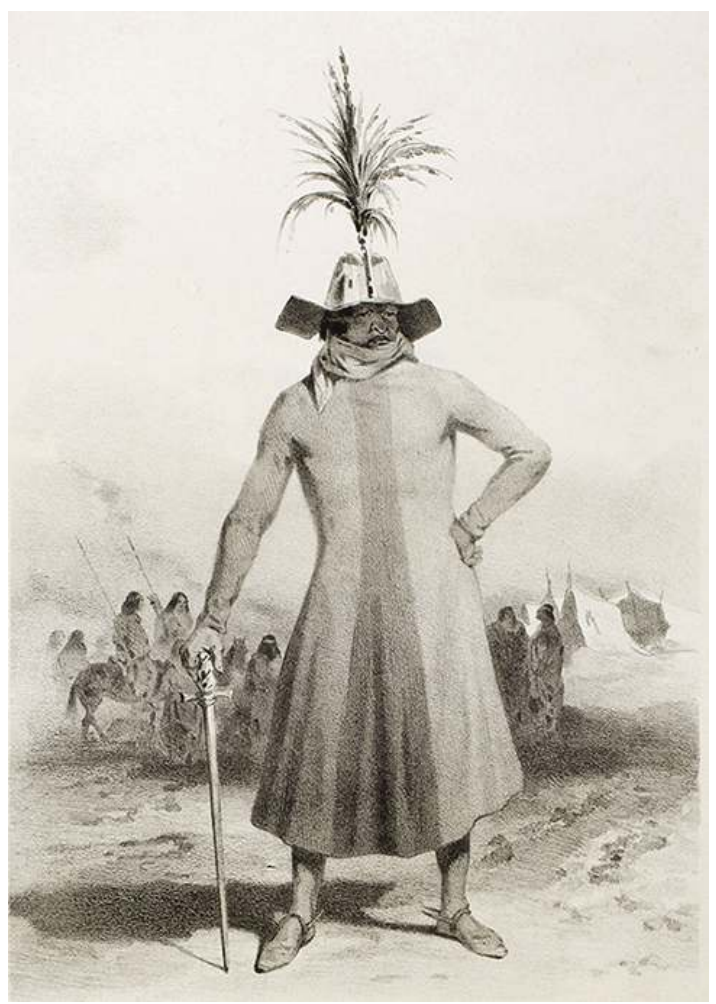

Imagen N 4. 1838. E. A. Goupil. Cacique patagón en traje de guerra (Konger). Litografía por Bayot, en J. Dumont D’Urville 1846, Tomo I, lámina 14, detalle (tomado de Del Carril 1992, p. 94)

Por su parte, los chilenos lo conocían como Huisel y los misioneros anglicanos Allen Gardiner y Robert Hunt como Wissale o Wesail ${ }^{55}$ (Hunt 1844-1845; Marsh 1857; Martinic 1997, 2000; 2007; Canclini en Coan 2006 [1886]). En 1842 Gardiner describió al cacique Wissale como un hombre muy poderoso, de un poco menos de $1,80 \mathrm{~m}$ de altura ${ }^{56}$ pero amplio en el pecho y en los hombros. El cacique le comunicó a Gardiner que estuvo ausente por ocho meses ya que fue a comprar caballos a Río Negro y en las conversaciones sostenidas con el marino y misionero británico, Wissale una vez más dejó claro su dominio del inglés. ${ }^{57}$ Es a través del relato de Gardiner que se dispone una fecha precisa para el fallecimiento de María: 1841. En una de sus conversaciones durante 1842 con el 
desertor conocido como San León, éste le expresa que llevaba 12 años viviendo con los tehuelches y que la "Vieja María" había muerto el año anterior (Marsh 1857).

El desertor de origen criollo San León, también conocido por los nombres de Centurión, Santos Santurión, Santorín, Santo Río (Fitz Roy 2016 [1839], Hunt 1844-1845; Marsh 1857; Coan 2006 [1886]; Llaras Samitier 1954, 1965; Martinic 2000, entre otros), ${ }^{58}$ es un personaje que me interesa traer a colación ya que permite situar espacial y temporalmente a Wissale, corroborando que éste, Konger y Congo son la misma persona, ya que San León aparece mencionado en los relatos como un subalterno del cacique del Estrecho de Magallanes (Marsh 1857; Coan 2006 [1886]). A su vez, su presencia también muestra la relación entre esta parcialidad y la de María, ya que San León en 1831 integra la comitiva que acompañó a María en su viaje a las islas Malvinas invitada por el gobernador Luis Vernet (Vernet 1831; Llaras Samitier 1965; Álvarez Saldivia 2016). Pero es quizás le mención que hace D'Orbigny sobre un "desertor chileno" que se encontraba entre los indígenas que fueron al Río Negro con uno de los hermanos de Vicente en 1829, la que nos permita volver a conjeturar sobre el parentesco entre aquel cacique de imprecisa identidad y María (D’Orbigny (1999 [1839-1847]).

\section{Palabras Finales}

Como ha quedado plasmado en numerosas fuentes documentales y trabajos de investigación, la cacica María fue sin duda una figura singular y destacada en la historia de la Patagonia. Tanto más si tenemos en cuenta que se trató de una mujer detentando poder y autoridad entre los tehuelches meridionales, por lo que la cuestión de género se constituyó en el centro de atención tanto de los cronistas como de los investigadores.

Como mencioné al principio de este trabajo, mucho ya se ha escrito sobre la historia de María, especialmente durante su adultez, por lo que una gran parte de estos datos han quedado fuera de este artículo. En su defecto, sobre la base de la información obtenida en mis propias investigaciones, me incliné por privilegiar y presentar información histórica, incluso de carácter inédito, sobre su familia y la primera etapa de su vida. Esta mirada genealógica estuvo también dirigida a echar luz sobre algunos aspectos no tan claros sobre sus orígenes, lazos parentales y los vínculos que su familia sostuvo con los establecimientos coloniales españoles a fines del siglo XVIII. Relación que incluso se prolongó luego de la disolución de los mismos, como lo demuestra el control que María ejerció sobre el ganado vacuno bagual introducido por el Fuerte San José en Península Valdés, como se desarrolló al principio de este trabajo.

Los indicios para proponer que María fue una indígena nacida en el seno de una familia tehuelche -posiblemente aónikenk- son de orden indirecto. Como vimos, Elizalde hasta el momento aporta el único indicio sobre una hija mujer para el cacique Vicente, utilizando el diminutivo de Mariquita para nombrar a la niña (Elizalde y Uztariz 1938 [1792]). Siguiendo a Llaras Samitier (1954) o Canclini (en Coan 2006 [1886]), es posible que la niña haya sido bautizada con un nombre cristiano en alguno de los establecimientos creados por los españoles a fines del siglo XVIII, siendo el más probable el Fuerte Nuestra Señora del Carmen, donde esta práctica era habitual. En este sentido, fue el lugar a donde los indígenas concurrían anualmente con el objeto de trabar comercio tanto con los pobladores como con otras parcialidades indígenas. A favor de ello, es importante mencionar el abandono de la colonia de Floridablanca en 1784, fecha en la cual 
probablemente no había nacido María, estimando su nacimiento en 1789. En el caso de Fuerte San José, en trabajos previos observamos que los primeros contactos con parcialidades de tehuelches meridionales fueron a partir de 1787/1788 y se caracterizaron por su carácter predominantemente hostil (ver Buscaglia 2015a, 2017). Finalmente, en el caso del establecimiento de la Real Compañía Marítima en Puerto Deseado, tampoco podría descartarse su posible bautismo en este enclave colonial, ya que María era una niña pequeña cuando su familia interactuó con el mismo. Esta información en su conjunto, permite cuestionar la idea de un origen mestizo o paraguayo de la cacica, no habiéndose registrado tampoco por el momento ninguna referencia a que la niña fuera adoptada de alguna otra parcialidad étnica. Considero que la confusión en torno al origen de María o incluso la negación de su origen tehuelche, merece una problematización y discusión más profundas a los efectos de visibilizar la colonialidad implícita que se reproduce en las narrativas históricas e historiográficas a lo largo del tiempo.

En cuanto al cacique Vicente queda claro que fue el padre de María, lo cual se ve reforzado por la transmisión del conocimiento del español, las estrategias para relacionarse con los europeos e incluso de símbolos materiales asociados al poder y la sacralidad, como la figura del Cristo. El lugar de liderazgo que ocupó su padre queda plasmado en las relaciones de parentesco y alianza con importantes caciques que detentaron su poder en distintos territorios de Patagonia meridional, tal como lo muestran las recurrencias en los relatos de distintos cronistas que circularon por la región a lo largo del tiempo.

71 Sin embargo, es escasa la información que se ha preservado hasta el presente sobre su madre, quien seguramente también le habría inculcado la habilidad para hablar el castellano. En cuanto a sus hermanos, solo hemos podido identificar a dos de ellos: el cacique Bysante o Vicente con una identidad mucho más clara, mientras que la del segundo se encuentra rodeada de un halo de ambigüedad. Tan solo por referencias indirectas, conjeturamos que pudo haberse tratado del cacique Congo, Konger, Wissale o Huisel, pero por el momento se trata de una hipótesis a seguir explorando en la medida que se reúna una mayor cantidad de evidencia.

72 El enfoque genealógico ha permitido también integrar información diversa sobre las relaciones intra como interétnicas en Patagonia meridional en el marco de la colonización española así como de la exploración y la explotación de recursos realizadas por otras naciones. La información recolectada acerca de la dinámica interétnica, indican el interés del cacique Vicente y líderes afines por convertirse en aliados de los españoles y receptores junto a su gente de los beneficios resultantes de dicha relación. Como he discutido en otros trabajos (Buscaglia 2012, 2015a, 2017), resulta necesario entender las maneras en que las sociedades nativas incorporaron al sistema colonial y su materialidad en sus dinámicos circuitos y paisajes (Schneider y Panich 2014). Esta perspectiva implica un desplazamiento hacia la forma en que el proceso colonial fue conceptualizado y en parte controlado por los indígenas, en lugar de centrarse únicamente en las prácticas asociadas a los colonizadores. Se espera así que los resultados generados contribuyan a ampliar el conocimiento en torno a las poblaciones indígenas y sus interacciones con los diversos actores que circularon por los confines de América del Sur entre los siglos XVIII y XIX. 


\section{Agradecimientos}

mejorar sustancialmente el presente trabajo. A la Dra. Marcia Bianchi Villelli por su atenta lectura y comentarios al manuscrito. Al personal del Archivo General de la Nación (Ministerio del Interior, Obras Públicas y Vivienda, Presidencia de la Nación), de la Academia Nacional de la Historia de la República Argentina y del Museo Etnográfico Juan B. Ambrosetti (FFyL-UBA), quienes gentilmente me han asesorado y colaborado en la búsqueda de los registros documentales. Una parte de los resultados presentados en este artículo se deriva de las investigaciones financiadas por los siguientes proyectos: PICT 2010-0050 (2011-2012), ANPCyT; PIP 0183 (2011-2013) y PIP 0759 (2014-2016), CONICET.

\section{Fuentes}

Aragón, A. (1810). Carta al Comandante del Fuerte Nuestra Señora del Carmen, Río Negro, 5 de septiembre. Sala X, legajo 2-3-15. Buenos Aires: Archivo General de la Nación.

Arredondo, N. (1793). Carta al Sr. Duque de la Alcaldía, Maldonado, [sin día] julio. Estado $80, n^{\circ}$ 3. Sevilla: Archivo General de Indias.

De la Peña, J. (1790). Carta al Comandante del Río de la Plata, Montevideo, 19 de febrero. Sala VII, Fondo Luis Vernet, legajo 127-9. Buenos Aires: Archivo General de la Nación.

De la Peña, J. (1791). Carta al Virrey Nicolás Arredondo, Montevideo, 2 de febrero, Patagonia. Expediciones, SGU, LEG,7306,1. Simancas: Archivo General de Simancas.

De la Peña, J. (1796a). Noticias de la costa patagónica por el piloto de la Real Armada, Don José de la Peña. Sala VII, Legajo 188. Buenos Aires: Archivo General de la Nación.

De la Peña. J. (1796b). Noticias de la Costa Patagónica por el piloto de la Real Armada, Don José de la Peña. MS-508 [4] DOC.1175. Río de Janeiro: Fundación Biblioteca Nacional Río de Janeiro.

Del Pozo, J. (s.f.). Retrato del cacique Junchar. № de catálogo 653. Madrid: Museo Naval.

Martínez, C. (1807). Carta al Capitán General de las Provincias Unidas del Río de la Plata, Río Negro, 28 de diciembre. Sala IX, Legajo 16-5-8. Buenos Aires: Archivo General de la Nación.

Muñoz, J. (1791). Oficio sin destinatario, Puerto Deseado, 4 de diciembre. Sala IX, Legajo 24-1-8. Buenos Aires: Archivo General de la Nación.

Muñoz, J. (1792). Carta al Virrey Nicolás Arredondo, Puerto Deseado, 6 de octubre. Sala IX, Legajo 16-4-9. Buenos Aires: Archivo General de la Nación.

84 Sin autor. (s.f.). Plano de Puerto Deseado en la costa patagónica. 48-A-14. Madrid: Museo Naval.

85 Vernet, L. (1831). Carta al Ministro Secretario de Gobierno, Malvinas, 22 de marzo. Sala VII Fondo Luis Vernet, Legajo 129, documento 84. Buenos Aires: Archivo General de la Nación. 


\section{BIBLIOGRAFÍA}

Alberti, J. y Buscaglia, S. (2015). Caracterización de los conjuntos artefactuales líticos del sitio Puesto de la Fuente (Estancia Manantiales, Península Valdés, Provincia de Chubut). Intersecciones en Antropología 16 (2), 397-409.

Alioto, S. L. (2011). Indios y ganado en la frontera. La ruta del Río Negro (1750-1830). Rosario: Protohistoria ediciones.

Álvarez Saldivia, A. (2016). William Low. Lobero del fin del mundo. Puerto Natales: Editorial Atelí.

Arias, F. y Méndez, L. M. (2008). Historias de mujeres patagónicas en los siglos XIX y principios del XX: unidad y diversidad a escala global. En III Jornadas de Historia de la Patagonia. (s/pp.). San Carlos de Bariloche, 6-8 de noviembre de 2008.

Bahamonde Gallardo, C. (2017). Dumont d'Urville al encuentro de los patagones. Colecciones Digitales, Subdirección de Investigación Dibam. [On line]. Disponible: http://www.museodemagallanes.cl/ sitio/Contenido/Objeto-de-Coleccion/Digital/83558:Dumont-d-Urville-al-encuentro-de-lospatagones.

Bandieri, S. (2014) Capítulo VI: La expansión de las fronteras. En Historia de la Patagonia. Colección Historia Argentina. (pp. 120-147). Buenos Aires: Sudamericana.

Bianchi Villelli, M. (2011). La “historia” del fuerte San José (península Valdés, 1779-1810). Primeros abordajes. En M. Ramos, A. Tapia, F. Bognanni, M. Fernández, V. Helfer, C. Landa, M. Lanza, E. Montanari, E. Néspolo y V. Pineau (eds.), Temas y problemas de la Arqueología Histórica. Tomo I. (pp. 55-68). Luján: Programa de Arqueología Histórica y Estudios Pluridisciplinarios (PROARHEP), Departamento de Ciencias Sociales, Universidad Nacional de Luján.

Bianchi Villelli, M. (2017). Colonialismo en Península Valdés: entre los proyectos defensivos y las tentativas comerciales (Patagonia norte, fines del siglo XVIII). Memoria Americana. Cuadernos de Etnohistoria 25 (1), 47-75.

Bianchi Villelli, M. (2018). El análisis químico de las aguas. Ciencia colonial, exploración y supervivencia en península Valdés a fines del siglo XVIII. Corpus. Archivos virtuales de alteridad americana 8 (2), 1-18.

Bianchi Villelli, M. y Buscaglia, S. (2015). De salvajes, de gestas y de mártires. Sentidos históricos sobre el fuerte San José en la historiografía tradicional (Península Valdés, Pcia. de Chubut, siglo XVIII). Revista del Museo de Antropología 8 (1), 187-200.

Bianchi Villelli, M., Buscaglia, S. y Sancci, B. (2013). Una genealogía de los planos históricos de los asentamientos coloniales del Fuerte San José, Península Valdés (Siglo XVIII). Corpus. Archivos virtuales de alteridad americana 3 (1), pp. 1-14.

Braun Menéndez, A. (1947). Ensayo de colonización en Puerto Deseado durante la época colonial. Anuario de Historia Argentina 1943-1945. (pp. 329-344). Buenos Aires.

Bianchi Villelli, M., Buscaglia, S., Calandrón, P. y Sellanes, A. (2019). Entre cerros y cañadones, el fuerte. Avances sobre el plano arqueológico del sitio Fuerte San José (Península. Valdés, Chubut). Revista Arqueología, Tomo 25 (en prensa). 
Briones, C. y Carrasco, M. 2000. Pacta Sunt Servanda. Capitulaciones, Convenios y Tratados con Indígenas en Pampa y Patagonia (Argentina 1742-1878). Buenos Aires: International Work Group for Indigenous Affairs y Vinciguerra Testimonios.

Buscaglia, S. (2011). La representación de las relaciones interétnicas en el discurso de Antonio Viedma (Patagonia Meridional, Siglo XVIII). Magallania 39 (2), 15-35.

Buscaglia, S. (2012a). Poder y dinámica interétnica en la colonia española de Floridablanca. Una perspectiva histórica y arqueológica (Patagonia, Argentina, Siglo XVIII). Saarbrücken: Editorial Académica Española.

Buscaglia, S. (2012b). El contacto en la práctica. La construcción social y material de las relaciones interétnicas en Floridablanca (Patagonia, Siglo XVIII). En Henderson, H. y S. Fajardo Bernal (comps.) La reproducción y la creación de desigualdades: Discusiones desde las teorías de agencia y práctica en la antropología suramericana. (pp. 99-122). Córdoba: Ed. Brujas.

Buscaglia, S. (2015a). Indígenas, borbones y enclaves coloniales. Las relaciones interétnicas en el Fuerte San José durante su primera década de funcionamiento (Chubut, 1779-1789). Corpus. Archivos Virtuales de Alteridad Americana 5 (1), 1-31.

Buscaglia, S. (2015b). Memorias de la negación y el estigma. La historización de las relaciones interétnicas en el Fuerte San José (Patagonia, siglos XVIII-XIX). Revista de Arqueología Histórica Argentina y Latinoamericana 9 (1), 5-36.

Buscaglia, S. (2017). Materiality and Indigenous Agency: Limits to the Colonial Order (Argentinean Patagonia, Eighteenth-Nineteenth Centuries). International Journal of Historical Archaeology 21 (3), 641-673.

Buscaglia, S. (s.f.). Relaciones interétnicas en Puerto Deseado, provincia de Santa Cruz (siglos XVIII-XIX). Un abordaje preliminar. Ms.

Buscaglia, S. y Bianchi Villelli, M. (2016). From Colonial Representation to Materiality: Spanish Settlements on Península Valdés (Patagonian Coast, 1779-1810). Historical Archaeology 50 (2), 69-88.

Buscaglia, S., Bianchi Villelli, M., Starópoli, L., Bosoni, C., Carelli, S., y Alberti, J. (2012). Arqueología histórica en península Valdés. Primeros abordajes históricos y arqueológicos al fuerte San José (1779-1810). Revista de Arqueología Histórica Argentina y Latinoamericana (6), pp. 47-79.

Caillet-Bois, R. (1948). Una tierra argentina. Las islas Malvinas. Buenos Aires: Ediciones Peuser.

Castillo Bernal, M. F. y Videla, L. (2003). Estudio comparativo de tres jefaturas femeninas en Patagonia. En V Congreso de Historia Social y Política Argentino-Chilena. (pp. 15-18). Trevelin, 9 al 11 de octubre de 2003.

Caviglia, S. (2012). Malvinas. Soberanía, Memoria y Justicia: 10 de Junio de 1829. Rawson: Ministerio de Educación de la Provincia de Chubut.

Canclini, A. (2006). María. Reina Tehuelche. Amor y poder en la Patagonia alrededor de un personaje insólito y olvidado pero de notable influencia. 1820-1843. Buenos Aires: Zaguier \& Urruty publicaciones.

Coan, T. (1833-1834). Two American missionaries visit the Tehuelche Indians at Gregory's Bay, 1833-1834. The Daily Journal of Rev. Titus Coan [extract]. [On line]. Disponible: http://patlibros.org/pjtc/ doc.php?wk=1 
Coan, T. (1880). Adventures in Patagonia. A misionary's exploring trips. New York: Dodd, Mead \& Company. [On line]. Disponible: https://archive.org/details/adventuresinpata00coan_0

Coan, T. (2006 [1886]). Aventuras en Patagonia. Un viaje de exploración de dos misioneros norteamericanos. Buenos Aires: Zaguier \& Urruty publicaciones.

Darwin, C. (1839). Journal and Remarks 1826-1836. En Narrative of the surveying voyages of his Majesty's ships Adventure and Beagle, between the years 1826 and 1836 describing their examination of the southern shores of South America and the Beagle circumnavigation of the Globe in Three volumes. Vol. III. London: Henry Colburn, Great Marlborough Street. [On line]. Disponible: https:// books.google.com.ar/books?id=UUWXjlu_JWQC\&pg=PR3\&dq=Journal+and+Remarks+1826-1836. +En+Narrative+of+the+surveying+voyages+of+his+Majesty\%E2\%80\%99s+ships+Adventure+and +Beagle,+between+the+years+1826+and+1836+describing+their+examination+of+the+southern +shores+of+South+America+and+the+Beagle+circumnavigation+of+the+Globe+in+Three+volumes. +Vol\&hl=es\&sa=X\&ved=0ahUKEwjizruN-57dAhVHUZAKHSdMAZQQ6AEINDAC\#v=onepage\&q=Journal \%20and\%20Remarks\%201826-1836.\%20En\%20Narrative\%20of\%20the\%20surveying\%20voyages\% 20of\%20his\%20Majesty\%E2\%80\%99s\%20ships\%20Adventure\%20and\%20Beagle\%2C\%20between\% 20the\%20years\%201826\%20and\%201836\%20describing\%20their\%20examination\%20of\%20the\% 20southern\%20shores\%20of\%20South\%20America\%20and\%20the\%20Beagle\%20circumnavigation \%20of\%20the\%20Globe\%20in\%20Three\%20volumes.\%20Vol\&f=false

Darwin, C. (2003 [1839]). Diario del Viaje de un naturalista alrededor del mundo. Buenos Aires: Elefante Blanco.

Davies, G. (2009). Rescates o compras indígenas en Carmen de Patagones (1795-1836): un fenómeno particular de mestizaje. En J. Farberman y S. Ratto (coords.), Historias Mestizas en el Tucumán Colonial y las Pampas (siglos XVII-XIX). (pp. 115-143). Buenos Aires: Biblos.

Del Carril, B. (1992). Los indios en la Argentina. Buenos Aires: Emecé Editores.

D’ Orbigny, A. (1999 [1835-1847]). Viaje por la América Meridional. Tomo II. Buenos Aires: Emecé Editores.

Dumrauf, C. (1991). Un precursor en la colonización del Chubut. Documentos sobre la actuación de Enrique Libanus Jones en el Chubut. Textos Ameghinianos. Chubut: Biblioteca de la Fundación Ameghino.

Elizalde y Ustáriz, J. J. (1938 [1792]). Viaje de la Corbeta San Pío a la costa patagónica y Tierra del Fuego en 179. Boletín de la Academia Chilena de la Historia Año 5, no 10, 252-339.

Enrique, L. A. (2011). La movilidad como estrategia en el uso del territorio norpatagónico a fines del siglo XVIII: funcionarios coloniales y grupos indígenas. Relaciones de la Sociedad Argentina de Antropología XXXVI, 361-368.

Enrique, L. A. (2012). Aproximaciones al paisaje hispano-indígena de fines del siglo XVIII a través de los documentos históricos generados en el contexto fronterizo del virreinato del Río de la Plata. Revista Memória em Rede, 2 (6), 155-169.

Enrique, L. A. (2018). Huellas del paisaje colonial en las narrativas fundacionales sobre la frontera sur. Buenos Aires: Sociedad Argentina de Antropología.

Fitz Roy, R. (2016 [1839]). Los viajes del Beagle. Informes de la segunda expedición (1831-1836). Colección Reservada del Museo del Fin del Mundo. Buenos Aires: Eudeba.

González, F. (1965 [1798]). Diario de Viaje que hizo por tierra de Puerto Deseado a Río Negro. En Cronistas y viajeros del Río de la Plata, prólogo y comentarios de A. M. Vignati, Tomo II. Buenos Aires: Academia Nacional de la Historia. 
Gorla, C. (1983). Origen y Evolución de la Ganadería Patagónica (1779- 1810). Buenos Aires: Fundación para la Educación, la Ciencia y la Cultura.

Hall, M. (1999). Subaltern voices? Finding the spaces between things and words. En Historical Archaeology: Back from the Edge. P. P. Funari, M. Hall y Siân Jones eds. (pp. 193-203). London: Routledge.

Haurie, V. (1996). Mujeres en tierra de hombres. Historias reales de la Patagonia invisible. Buenos Aires: Sudamericana.

Hunt, R. (1844-1845). Journal of Robert Hunt Esquire relative to the period during which he participated with Captain Allen Gardiner R. N. in an attempt to establish an anglican mission on the patagonian shores of the Straits of Magellan. [On line]. Disponible: http://patlibros.org/dlpdf/jrh.pdf

Irurtia, M. P. (2002). La visión de los indios respecto de los "cristianos" y "huincas" en el norte de la Patagonia, siglos XVIII y XIX. En L. R. Nacuzzi (comp.) Funcionarios, diplomáticos, guerreros. Miradas hacia el otro en las fronteras de Pampa y Patagonia (Siglos XVIII y XIX). (pp. 247-285). Buenos Aires: Sociedad Argentina de Antropología.

Johnson, M. (1996). An Archaeology of Capitalism. Oxford: Blackwell.

Jones, S. (1999). Historical categories and the praxis of indentity: the interpretation of ethnicity in historical archaeology. En Historical Archaeology from the Edge. (pp. 219-232). London: Routledge.

King, P. P. (2015 [1839]). Los viajes del Beagle. Informes de la primera expedición (1826-1830). Colección Reservada del Museo del Fin del Mundo. Buenos Aires: Eudeba.

Lehmann-Nitsche, R. (1914). Noticias etnológicas sobre los antiguos patagones recogidas por la expedición Malaspina en 1789. Boletín de la Academia Nacional de Ciencias de Córdoba, Tomo 20, 103-112.

Llarás Samitier, M. (1954). La india María. Una mujer que capitaneó a los tehuelches del Estrecho. Argentina Austral 227, 10-13.

Llarás Samitier, M. (1965). La india María en las Islas Malvinas. Argentina Austral 409, 13-16.

Llarás Samitier, M. (1985). María Grande o María Vieja, la india cacique de los tehuelches. Revista Patagónica 22, Año IV, 17-18.

Luiz, M. T. (2006). Relaciones Fronterizas en Patagonia. La Convivencia Hispano-Indígena a Fines del Período Colonial. Ushuaia: Asociación Hanis, Universidad Nacional de la Patagonia San Juan Bosco.

Maeso Buenasmañanas, J. A. (2010). La expedición de Juan José de Elizalde y Uztáriz a la Patagonia, Tierra del Fuego e Isla de los Estados (Diciembre 1791-Febrero 1792). En Martínez Shaw, C. y Alfonso Mola, M. (coords.) España en el Comercio Marítimo Internacional (Siglos XVII-XIX). Quince Estudios. (pp. 426-460). Madrid: Universidad Nacional de Educación a distancia.

Mallon, F. (1994). The promise and dilemma of subaltern studies: perspectives from Latin American History. The American Historical Review 99 (5), 1491-1515.

Marsh, J. W. (1857). A memoir of Allen F. Gardiner, Comander, R. N. Londres: Impreso por Janes Nisbet and Co. [On line]. Disponible: https://books.google.com.ar/books?

$\mathrm{id}=\mathrm{a} 6$ pDAQAAMAAJ \& printsec $=$ frontcover $\& \mathrm{dq}=\mathrm{A}+$ memoir + of + Allen $+\mathrm{F}$. +Gardiner\&hl=es\&sa=X\&ved=0ahUKEwjQ2Mz8_p7dAhVGi5AKHYkOBYgQ6AEIJzAA\#v=onepage\&q=A \%20memoir\%20of\%20Allen\%20F.\%20Gardiner\&f=false

Martínez Shaw, C. (2008). Economía e imperio. Los establecimientos de la Real Compañía Marítima en América. Anuario de Estudios Atlánticos 54-I, 593-630.

Martinic, M. (1977). Historia del Estrecho de Magallanes. Santiago: Ed. Andrés Bello. 
Martinic, M. (1995). Los Aónikenk. Historia y cultura. Punta Arenas: Ediciones de la Universidad de Magallanes.

Martinic, M. (1997). Las misiones cristianas entre los aónikenk. Una historia de frustraciones. Anales del Instituto de la Patagonia 28, 45-52.

Martinic, M. (2000). Informaciones etnográficas extraídas del diario inédito de Santiago Dunne, secretario de la Gobernación de Magallanes (1845). Anales del Instituto de la Patagonia 25, 6-25.

Martinic, M. (2007). Documentos inéditos para la historia de Magallanes. "Memorandum referido a los patagones". Magallania (35) 2,159-164.

Martinic, M. (2008). El comercio sexual entre las mujeres aónikenk y los foráneos. Magallania 36 (1), 31-36.

Mayorga, M. (2016). Antecedentes históricos referidos a la caza de lobos marinos y su interacción en el medio geográfico y humano en el extremo austral americano: el caso del lobero escocés William Low. Magallania 44 (2), 37-64.

Moreland, J. (2006). Archaeology and texts. Subservience or Enlightenment. Annual Review of Anthropology 35, 135-151.

Nacuzzi, L. R. (1993-94). Los cacicazgos duales en Pampa-Patagonia durante el siglo XVIII. Relaciones XIX, 135-144.

Nacuzzi, L. R. (2005). Identidades impuestas. Tehuelches, aucas y pampas en el norte de la Patagonia.

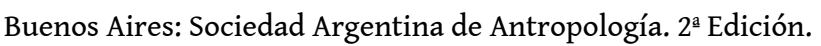

Nacuzzi, L. R. (2008). Repensando y revisando el concepto de cacicazgo en las fronteras del sur de América (Pampa y Patagonia). Revista Española de Antropología Americana 38 (2), 75-95.

Novo y Colson, P. (1885). Viaje Político Científico alrededor del mundo por las Corbetas Descubierta y Atrevida al mando de los Capitanes de Navio Don Alejandro Malaspina y Don José de Bustamante y Guerra desde 1789 a 1794. Madrid: Imprenta de la viuda e hijos de Abienzo.

Palermo, M. A. (1994). El revés de la trama. Apuntes sobre el papel económico de la mujer en las sociedades indígenas tradicionales del sur argentino. Memoria Americana. Cuadernos de Etnohistoria 3, 63-83.

Priegue, C. N. (1971). La información etnográfica de los patagones del siglo XVIII en tres documentos de la expedición Malaspina (1789-1794). Textos comentados 3. Cuadernos del Sur. Bahía Blanca: Instituto de Humanidades. Universidad Nacional del Sur.

Quijada, M. (2002). Repensando la frontera sur argentina: concepto, contenido, continuidades y discontinuidades de una realidad espacial y étnica (siglos XVIII-XIX). Revista de Indias 62 (224), 103-142.

Rey Timas, L. (1960). María, matricia indiana que conoció Fitz Roy. Argentina Austral 350, 20-21.

Ratto, H. (1930a). Expedición de la corbeta San Pío y bergantín Nuestra Señora del Carmen a la costa oriental de Tierra del Fuego. En Actividades marítimas en la Patagonia durante los siglos XVII y XVIII. (pp.175-184). Buenos Aires: Ministerio de Marina. Dirección general de navegación y comunicaciones.

Ratto, H. (1930b). Expedición del capitán de fragata Don Juan Gutiérrez de la Concha al Golfo San Jorge. En Actividades marítimas en la Patagonia durante los siglos XVII y XVIII. (pp. 185-194). Buenos Aires: Ministerio de Marina. Dirección general de navegación y comunicaciones.

Sáenz de Méndez, E. (1982). María de las Islas. Buenos Aires: Editorial Latinoamericana. 
Sagredo Baeza, R. y González Leiva, J. I. (2004). La expedición de Malaspina en la frontera austral del imperio español. Chile: Editorial Universitaria, Centro de Investigaciones Diego Barros Arana, Dirección de Bibliotecas, Archivos y Museos.

Schneider, T. D. y Panich, L. M. (2014). Native agency and the margins of empire. Indigenous landscapes, Spanish missions, and contested histories. En Schneider, T. D. y L. M. Panich (eds.), Indigenous Landscapes and Spanish Missions: New Perspectives from Archaeology and Ethnohistory. (pp. 5-22). Arizona: University of Arizona Press.

Segura, J. J. A. (1974). Don Manuel Lefrant y los “memorables acontecimientos" de una navegación por Puerto Deseado, Tierra del Fuego e Islas Malvinas (1791-1792). En Segundo Congreso de Historia Argentina y Regional, Tomo I. Buenos Aires: Academia Nacional de la Historia.

Sosa, N. (2001). Mujeres indígenas de la Pampa y la Patagonia. Buenos Aires: Emecé Editores.

Vargas y Ponce, J. (1788). Relación del Último Viaje al Estrecho de Magallanes de la Fragata de S. M. Santa María de la Cabeza en los años de 1785 y 1786. Noticias de los Habitantes, Suelo, Clima y Producciones del Estrecho. Madrid: Impreso por la viuda de Ibarra, hijos y Cía. [On line]. Disponible: https://archive.org/details/A255088

Videla, L. (2007). María, cacica de los tehuelches. Todo es Historia 477, 28-35.

Videla, L. y del Castillo Bernal, M. F. (2003). Reinas y guerreros. Sobre jefaturas indígenas en la Patagonia meridional. En IX Jornadas Escuela/Departamentos de Historia, publicación digital.

Córdoba.

Viedma, A. (1972a [1783]). Diario de Viedma. En Colección Pedro De Angelis, Tomo VIII, volumen B. (pp. 845-936). Buenos Aires: Plus Ultra.

Viedma, A. (1972b [1783]). Descripción de la costa meridional del sur llamada vulgarmente patagónica. En Colección Pedro De Angelis, Tomo VIII, vol. B. (pp. 937-966). Buenos Aires: Plus Ultra.

Vignati, M. A. (1940). Materiales para la lingüística patagona. El vocabulario de Elizalde. Boletín de la Academia Argentina de Letras, Tomo VIII, 159-202.

Weber, D. J. (1998). Borbones y bárbaros. Centro y periferia en la reformulación de la política de España hacia los indígenas no sometidos. Anuario del IEHS 13, 147-171.

\section{NOTAS}

1. El complejo de asentamientos coloniales conformados por el Fuerte San José y el Puesto de la Fuente (Península Valdés, provincia de Chubut) son objeto de investigación desde la perspectiva de la arqueología histórica desde el año 2010 (Bianchi Villelli 2011, 2017, 2018; Bianchi Villelli y Buscaglia 2015; Bianchi Villelli et al. 2013; Bianchi Villelli et al. 2019; Buscaglia 2015a, 2015b, 2017; Buscaglia et al. 2012; Alberti y Buscaglia 2015; Buscaglia y Bianchi Villelli 2016, entre otros).

2. Archivo General de la Nación (AGN), Sala X, legajo 2-3-15.

3. Archivo General de la Nación, Sala VII, Fondo Luis Vernet, Legajo 129, documento 84.

4. El análisis de la bibliografía ha permitido identificar al artículo de Llarás Samitier (1965) como la fuente sobre los detalles de la visita de la cacica a las islas mencionada al pasar por R. Fitz Roy (2016 [1839]) y Caillet-Bois (1948). Estos detalles fueron reproducidos en ulteriores trabajos y novelas. Sin embargo, las pesquisas realizadas en las fuentes primarias consultadas en el Archivo General de la Nación, como el fondo Luis Vernet (Sala VII) o los legajos correspondientes a las Islas Malvinas (Sala X), no han arrojado resultados positivos al respecto por el momento, a excepción del documento mencionado en la nota precedente en el que tan solo se menciona en 
cuanto a los indígenas del Estrecho de Magallanes que su "personaje principal visitó" las islas. Resta profundizar las investigaciones e incluso, consultar en el archivo de la cancillería.

5. Los sesgos en las fuentes documentales se encuentran relacionados con del contexto social político e ideológico en el que fueron producidas; las posiciones e intereses de sus autores, los tiempos de las observaciones e interacciones, la naturaleza de los documentos, las audiencias hacia los cuales estaban destinadas, la construcción y negociación de las identidades sociales, entre otras cosas (Jones 1999).

6. El listado de las fuentes primarias citadas en el artículo puede encontrarse en el apartado "Fuentes históricas inéditas" en las referencias bibliográficas.

7. La Bahía de San Gregorio fue un paradero tradicional de los aónikenk, recurrentemente utilizado a lo largo del tiempo y documentado por numerosos cronistas (Martinic 1977).

8. Cabe mencionar la ausencia de referencias en el diario de Antonio Viedma, tanto sobre el avistaje como el contacto con indígenas, durante el período -abril a noviembre de 1780- que permaneció en Puerto Deseado junto a la expedición destinada a fundar más tarde la colonia de Floridablanca en la Bahía de San Julián, provincia de Santa Cruz (Viedma 1972a [1783]).

9. Se refiere a la captura del cacique Julián Camelo en el Fuerte San José qué desencadenó su traslado y asesinato en las inmediaciones del Fuerte Nuestra Señora del Carmen en el mes de junio de 1788 (Nacuzzi 2005; Buscaglia 2015a). El cacique Julián lideró a la parcialidad de tehuelches meridionales que interactuaron pacíficamente con la colonia Floridablanca durante sus tres años de funcionamiento (1780-1784) (Viedma 1972a [1783]; Buscaglia 2011, 2012a y b, 2017).

10. De acuerdo a varios indicios suministrados por los integrantes de la expedición comandada por Alejandro Malaspina, esta parcialidad habría sido la que interactuó de forma estrecha con la colonia de Floridablanca (Bahía de San Julián, provincia de Santa Cruz). Como se presenta a lo largo de este acápite, prueba de ello sería el vínculo con los pilotos José de la Peña y Bernardo Tafor así como con el Superintendente Don Antonio Viedma, el dominio del castellano e incluso la referencia a la posesión y al uso ritual - en forma similar a la figura del Cristo como se mostrará más adelante- de un mascarón de proa atribuido a la Fragata inglesa Tamer naufragada en Puerto Deseado (Pineda en Priegue 1971, p. 22; De la Peña en Lehmman-Nitsche 1914, p. 10). Al respecto es importante recordar que Antonio Viedma también da cuenta de la tenencia de mascarones de proa o figuras de las aletas de la popa de embarcaciones, como parte de los objetos sagrados poseídos entre los indígenas con los interactuó y observó mientras fue superintendente de la colonia de Floridablanca entre 1780 y 1783 (Viedma 1972b [1783], p. 954).

11. En dicha publicación se incluyen tres documentos registrados en el Archivo del Museo Naval de Madrid como: "Descripción de los patagones" (Mss. 343, doc. 19), "Noticias sobre los patagones y Puerto Deseado" (Mss. 100, doc. 10) y "Descripción de los patagones” (Mss. 124, doc. 5). De acuerdo a las pesquisas realizadas por la autora, los dos primeros corresponden al Teniente Coronel Don Antonio de Pineda, quien formó parte de la tripulación de la corbeta "La Descubierta" y estuvo a cargo de los ramos de Historia Natural. El tercer documento es atribuido al hermano del anterior, Don Arcadio Pineda quien se embarcó en la corbeta "La Atrevida" como oficial subalterno (Priegue 1971, p. 5).

12. AGN, Sala VII, Fondo Luis Vernet, legajo 127-9.

13. Entre 1785 y 1786 en las inmediaciones de Cabo Vírgenes (provincia de Santa Cruz) la expedición al mando de Antonio de Córdoba se contacta tanto con "patagones" como con indígenas canoeros. En cuanto a los primeros, destacaba su manejo del castellano como resultado del contacto con las colonias patagónicas así como el uso de prendas y objetos de origen español. Lo cual es reafirmado con mayor detalle cuando afirma que al frente de los mismos se encontraba uno que decía llamarse Francisco Xavier, vestido con un poncho de pañete, un traje de los que usan los criollos en la América meridional y un quillango de guanaco. Además, llevaba un "sable o machete" con vaina de bayeta y tenía grabado en la hoja "Por el Rey Carlos III". Este grupo 
indígena manifestó haberse relacionado con la colonia de Floridablanca, al hacer mención de su conocimiento del "Capitán" Antonio Viedma y del Piloto Bernardo Tafor. El observador estima que el grupo estaba conformado por aproximadamente 300 o 400 individuos, aunque no contabilizó a las mujeres, que según él quedaron en las tolderías (Vargas y Ponce 1788, pp. 20-21). 14. Llama la atención que el teniente de navío mencione relaciones pacíficas entre esta parcialidad tehuelche y el Fuerte San José. Mis investigaciones sobre las relaciones interétnicas en este escenario indican no sólo un trato muy esporádico, sino de carácter hostil a partir de 1787 cuando empiezan a registrarse las primeras interacciones con indígenas (Buscaglia 2015a, 2017). Sin embargo, no es posible descartar el desarrollo de interacciones pacíficas pero que no fueran mencionadas por en el registro documental.

15. Es llamativo que en este pasaje Malaspina haga referencia a la "colonia de Puerto Deseado", ya que cuando recala en este puerto el establecimiento de la Real Compañía Marítima aún no se había fundado. O bien Malaspina confunde Puerto Deseado con Puerto San José o bien hace referencia al campamento provisional que en 1780 Antonio Viedma comandó en dicho puerto. Sin embargo, como referimos en la nota 7, ni en los oficios ni en el diario de Viedma se refiere al avistaje o contacto con indígenas durante la estadía.

16. Se refiere a la "Nueva colonia y Fuerte de Floridablanca (Puerto San Julián, provincia de Santa Cruz).

17. Recocido también como hermano de Julián Camelo y bautizado así en abril de 1780 por la expedición colonizadora de Antonio Viedma (Viedma 1972a [1783], p. 905)

18. Dado que la forma de escribir los nombres propios de los caciques solía variar según la fonética, es posible que De la Peña haga referencia al cacique Chegues, a quien también menciona más adelante en su oficio como Cheigues (De la Peña 1790, folio 10).

19. Capón podría corresponderse con el Cohopan o Copán de Antonio Viedma, quien señala que dominaba los territorios aledaños al Río Santa Cruz y el Estrecho de Magallanes, según el documento del que se trate respectivamente (Viedma 1972a [1783], p. 906 y Viedma 1972b [1783], p. 943).

20. Vale la pena destacar el precedente del Cacique Capón en cuanto a su visita a las Islas Malvinas, tal como años más tarde lo hiciera María. Al respecto, es interesante señalar también como algunos integrantes de las parcialidades de tehuelches meridionales se habituaron a abordar las embarcaciones para realizar largas travesías, en muchos casos destinadas a negociar con los europeos y criollos.

21. AGN, Sala IX, Legajo 16-5-8.

22. Un análisis más extenso de las relaciones interétnicas en el contexto del enclave de la Real Compañía Marítima formará parte de otra publicación (Buscaglia s.f).

23. AGS, Patagonia. Expediciones, SGU, LEG, 7306, 1.

24. Ello puede obedecer tanto a omisiones en las fuentes documentales como a la fragmentariedad del corpus relevado en el Archivo General de la Nación. Sin embargo, Martínez Shaw señala por su parte la escasez de noticias sobre la Real Compañía Marítima entre agosto de 1792 y marzo de1802, aun teniendo acceso directo a la documentación histórica existente en los repositorios españoles. El autor atribuye esta falta de información "a la paralización de los negocios de la compañía como consecuencia de la guerra con Inglaterra que tiene al Atlántico como un escenario privilegiado, aunque sabemos que las campañas para la captura de lobos y leones marinos se prosiguieron durante estos años, pero que fue muy difícil o tal vez imposible la remisión del producto obtenido a España" (Martínez Shaw 2008, p. 616).

25. AGN, Sala IX, Legajo 24-1-8.

26. La interacción entre la sociedad hispano-criolla e indígena en el contexto de la Patagonia oriental de fines del siglo XVIII fue un proceso complejo, tanto a nivel sincrónico como diacrónico. En términos generales se caracterizó por relaciones pacíficas, pero en el marco de un delicado equilibrio que a veces solía romperse con facilidad. En este contexto la negociación y la 
ambivalencia en la estructuración de las relaciones interétnicas habrían sido el denominador común, cuya comprensión depende de las condiciones particulares de los contextos en los que tuvo lugar la interacción (Nacuzzi 2005; Luiz 2006; Buscaglia 2011, 2012a, 2015a, Buscaglia 2017, s.f, entre otros).

27. En el caso particular de las colonias patagónicas, la política pacificadora impulsada por los borbones (Weber 1988) buscaba por un lado evitar que los indígenas se convirtieran en aliados de otras potencias extranjeras como ocurrió en América del Norte por ejemplo; siendo una de las preocupaciones de España en este período el avance británico y portugués sobre sus posesiones en el Atlántico Sur. Por otro lado, permitía asegurar también la continuidad de la empresa de poblamiento, dado el contexto de marcada inestabilidad y desabastecimiento característicos de las empresas coloniales españolas en sus momentos iniciales. De este modo, se buscaba incentivar el intercambio y comercio con los indígenas, desalentando posibles actos de hostilidad contra los enclaves coloniales (Gorla 1983; Weber 1998; Nacuzzi 2005; Luiz 2006; Buscaglia 2012, 2015a, entre otros). Sin embargo, a diferencia de América del Norte, durante el siglo XVIII en Patagonia no existió una mercantilización a gran escala de los artículos producidos por los nativos patagónicos -pieles, plumas, carne fresca. Por el contrario, éstos se situaron en un nivel de abastecimiento eventual y de índole local.

28. AGN, Sala IX, legajo 16-4-9.

29. AGI, Estado 80, nำ 3 .

30. Las relaciones con las tripulaciones de las embarcaciones, especialmente loberas y balleneras, pudo haber implicado incluso el comercio sexual. Si bien existen muy escasas referencias históricas al respecto como es de esperarse, he registrado al menos un documento de fines del siglo XVIII que da cuenta de esta práctica en el contexto de la factoría pesquera de Puerto Deseado (De Victorica 1790 en Braun Menéndez 1947). Asimismo, cabe destacar las noticias dadas por un tripulante del ballenero francés Fanny en 1837 así como aquellas suministradas en 1845 por el gaucho Centurión -integrante primero del grupo liderado por María y luego del cacique Wissel- a Santiago Dunne, secretario de la Gobernación de la colonia de Magallanes. En estos dos últimos casos la margen septentrional del Estrecho de Magallanes fue el escenario por excelencia para el intercambio de favores sexuales por parte de las mujeres aónikenk a cambio de artículos de origen europeo (Martinic 2000, 2008).

31. Tanto P. P. King como C. Darwin señalaron el comercio frecuente de María y su grupo con los loberos -particularmente con William Low- y balleneros que navegaban por las aguas patagónicas, canjeando sus cueros, carne, mantas y pieles por cuentas, cuchillos, abalorios, ornamentos de bronce, azúcar, harina y sobre todo bebidas alcohólicas como el aguardiente (Darwin 2003 [1839]; King 2015 [1839]; Álvarez Saldivia 2016). La costumbre dictaba el traslado de la cacica y su gente a las embarcaciones, donde en ocasiones pasaban la noche.

32. AGN, Sala VII, Legajo 188 y FBNRJ, MS-508 [4] DOC.1175. Ambos documentos corresponden al mismo informe, con la diferencia que el segundo está completo.

33. Si bien no es posible aseverar que Jonafa y Cogocha sean de la misma persona, es sugerente que en ambos casos los diversos cronistas destaquen el dominio del castellano y la amistad con el piloto De la Peña.

34. Como resultado de mis investigaciones he observado que en algunos de los artículos (i.e. Sosa 2001, Videla 2007; Videla y del Castillo Bernal 2007) que refieren brevemente a la infancia y a los progenitores de la cacica María, se cita como fuentes de estos datos los trabajos que tratan sobre Elizalde de Héctor Ratto "Actividades marítimas en la Patagonia durante los siglos XVII y XVIII" (1930) y el trabajo de Milcíades A. Vignati "Materiales para la lingüística patagona. El vocabulario de Elizalde" (1940). En el primer caso, la consulta del capítulo "Expedición de la corbeta San Pío y bergantín Nuestra Señora del Carmen a la costa oriental de Tierra del Fuego (Ratto 1930a, pp. 175-184), no arrojó resultados positivos al respecto. En el segundo caso, cuando consulté un ejemplar del trabajo de Vignati en la Academia Nacional de la Historia, encontré que el autor no 
solo no suministra referencias relativas a la infancia y lazos familiares de María, sino tampoco se encuentran transcriptos los pasajes del diario de Elizalde, a excepción del vocabulario recopilado entre los indígenas patagónicos en Puerto Deseado, objeto de la publicación. No obstante, Vignati sí menciona la localización de una transcripción del diario del teniente de navío en el repositorio del Museo Etnográfico (FFyL-UBA). Sobre la base de este dato, el mismo fue identificado, digitalizado y analizado para el presente trabajo (Elizalde y Uztariz 1938 [1792]). Por lo tanto, desconozco cuál es la fuente real utilizada para obtener la información sobre la primera etapa de la vida María. Es probable que se trate de un error de citación reproducido a lo largo del tiempo. 35. Se utilizó la transcripción del diario de Elizalde publicada en el Boletín de la Academia Chilena de la Historia (Elizalde y Uztariz 1938 [1792]). Actualmente, el documento original se encuentra en el Archivo de Museo Naval de Madrid, MS 99, documento 3, folios 44-107 (Maeso Buenasmañanas 2010).

36. Si bien durante el período virreinal fueron moneda corriente los pactos y las alianzas que garantizaban la paz y la ayuda en la frontera sur de la capital virreinal (Briones y Carrasco 2000; Quijada 2002), en el caso de las parcialidades tehuelches de Patagonia meridional, no he encontrado por el momento referencias a su intervención en este tipo de alianzas políticas con la esfera gubernamental. Por el contrario, de las mismas sólo formaban parte distintas comunidades indígenas de Pampa y Patagonia, particularmente de la porción cordillerana y septentrional de la región, posiblemente por su cercanía a los centros de poder coloniales (Gorla 1983; Briones y Carrasco 2000; Quijada 2002; Nacuzzi 2005; Luiz 2006; Alioto 2011, entre otros). No obstante, la negociación habría sido el denominador común en la articulación de las relaciones interétnicas en los contextos presentados en este trabajo. De acuerdo a Luiz, estos modos de interacción no solo fueron resultado de la revisión de las políticas fronterizas y de cambios en los dispositivos de poder hispano-criollos, sino también de la reelaboración de estrategias por parte de los indígenas (Luiz 2006). En este sentido, el sistema de dádivas implementado por el gobierno colonial para asegurarse la lealtad y colaboración de los indígenas, principalmente de sus caciques, también contribuirá a reforzar los lazos de interdependencia y complementariedad (Luiz 2006; Quijada 2002). Sin embargo, a pesar de las conocidas consecuencias negativas de estos procesos a largo plazo, las comunidades indígenas supieron aprovechar las ventajas que les representaba en términos políticos, económicos y sociales la negociación con la fracción hispano-criolla. Como señala Quijada (2002) la incorporación de productos en tanto bienes de prestigio, pasó a formar parte de las redes de reciprocidad que sustentaban formas de sociabilidad y autoridad indígenas, tanto intra como intertribales.

37. Capitán de la marina mercante y comerciante (Martínez Shaw 2008).

38. Las relaciones fraternales entre estos tres caciques son también corroboradas por Juan Muñoz en un oficio de octubre de 1792 (Muñoz 1792).

39. Mencionado también por el Piloto de la Peña (1790).

40. La interacción y negociación con los navegantes a bordo de sus embarcaciones será una de las prácticas que María mantuvo y supo desplegar estratégicamente en numerosas oportunidades durante su vida adulta, tal como lo reflejan diversas las fuentes históricas que hacen referencia a la cacica.

41. Sic. En castellano en el original.

42. Sic. En castellano en el original.

43. Sic. En castellano en el original.

44. Sic. En castellano en el original.

45. Ceremonia que es descripta con detalle por P. P. King (2015 [1839], pp. 107-108).

46. P. P. King al describir como estaba vestida María, menciona que llevaba puestos "unos aros hechos de medallas con la figura de la Virgen María estampada", los cuales junto con un alfiler de bronce le fueron entregados por un lobero norteamericano de apellido Lewis (King 2015 [1839], pp. 105). 
47. Esta es la primera referencia que encuentro en el marco de mis pesquisas de un nombre español para el cacique Capón.

48. En otros documentos aparece como Charcoala, Chacuala o Sacuala (Muñoz 1791; Elizalde 1938 [1792]; González 1965 [1798]; De la Peña 1791).

49. Al igual que Lefrant (en Segura 1974), Elizalde señala que, dado que Chacuala estuvo desde su infancia en contacto con los españoles de Puerto San Julián, "habla medianamente el castellano, es bastante despejado, y muy adicto a los nuestros” (Elizalde y Uztáriz 1938 [1792], p. 266).

50. Con una diferencia de nueve años, tanto Elizalde (1938 [1792]) como Antonio Viedma (1972b [1783]) reconocen respectivamente en sus diarios a este cacique como aquel que dominaba el territorio de Puerto Deseado.

51. Sic. En castellano en el original.

52. Sic. En castellano en el original.

53. Recordemos la cita de P. P. King al comienzo de este acápite.

54. En diario original, disponible en la Biblioteca del Congreso (Washington DC), Coan detalla que Congo habría aprendido el inglés a partir del contacto con marinos británicos y norteamericanos (disponible en: http://patlibros.org/pjtc/doc.php?wk=1).

55. Martinic señala que el dominio territorial de Wissale abarcaba el distrito situado en el estrecho de Magallanes -incluida la parte norte de la península de Brunswick- y el río Gallegos (Martinic 2007).

56. Si bien la información suministrada por Gardiner respecto de la altura de Wissale difiere en unos $10 \mathrm{~cm}$ centímetros de aquella consignada por Dumont d'Urville (Dumont d'Urville 1841 en Bahamonde Gallardo 2017), ello podría ser producto de una apreciación subjetiva de ambos observadores.

57. Sin embargo, a pesar que tanto Coan como Gardiner manifiestan el dominio del inglés del cacique, Robert Hunt compañero de Gardiner en su misión evangelizadora de los tehuelches del Estrecho de Magallanes, expresa en su diario que Wesail sólo habló en castellano con Gardiner. Es posible que el cacique dominara mejor este idioma y prefiriera utilizarlo como lengua franca, por sobre el inglés.

58. A pesar de haber consultado una amplia diversidad de fuentes bibliográficas, no queda claro el origen -chileno o uruguayo- de este gaucho desertor. De acuerdo a Llaras Samitier, San León pudo haber llegado a las Islas Malvinas cumpliendo una condena de destierro. Luego habría sido enviado al estrecho de Magallanes por Mathew Brisbane y Luis Vernet, en ese entonces gobernador de las islas, a comprarle caballos a los indígenas (Fitz Roy 2016 [1839]). Fue allí donde habría encontrado la oportunidad de escapar a su condena e integrarse al grupo de la cacica María (Llaras Samitier 1965). En 1847 falleció a bordo de la goleta Voladora como resultado de una disentería mientras regresaba de un viaje a la capital chilena (Martinic 2000).

\section{RESÚMENES}

A partir de mis investigaciones sobre la estructuración de las relaciones interétnicas en el marco de la colonización española de la costa patagónica a fines del siglo XVIII, en este trabajo presentaré información relativa a la genealogía de la cacica María. Desde este punto de vista, ofreceré argumentos a favor no sólo de su origen tehuelche, sino de los vínculos que su familia mantuvo con los enclaves coloniales mencionados, especialmente con el establecimiento de 
Puerto Deseado (provincia de Santa Cruz). En este sentido, me interesa incorporar tanto información histórica inédita así como fuentes éditas, aunque poco profundizadas en la bibliografía consultada. Más allá de la genealogía de la cacica, a partir de la información presentada en este trabajo se busca también contribuir al conocimiento sobre las relaciones tanto intra como interétnicas así como los territorios de los tehuelches meridionales en la transición de los siglos XVIII a XIX, marcados por profundos cambios políticos y sociales.

Based on my research on the structuring of interethnic relations in the framework of the Spanish colonization of the Patagonian coast in the late 18th century, in this paper I will present information about the genealogy of Cacica María. I will offer arguments for not only her tehuelche origin, but about the ties that her family holds with the aforementioned colonial enclaves, especially with the settlement of Puerto Deseado (Santa Cruz province). In this regard, I am interested in incorporating both unpublished historical information as well as sources edited, although scarcely deepened in the bibliography consulted. Beyond the genealogy of the cacica, it also sought to contribute to knowledge about both intra and interethnic relations as well as the territories of southern tehuelches in the transition from the 18th to 19th centuries, marked by deep political and social changes.

\section{ÍNDICE}

Keywords: Cacica María, Patagonia, colonialism, intra and interethnic relations.

Palabras claves: Cacica María, Patagonia, colonialismo, relaciones intra e interétnicas

\section{AUTOR}

\section{SILVANA BUSCAGLIA}

Instituto Multidisciplinario de Historia y Ciencias Humanas- Consejo Nacional de Investigaciones Científicas y Técnicas-Argentina

Correo electrónico: silvana_buscaglia@yahoo.com.ar 